\title{
Strategic Plan for the Factory Automation Systems Division
}

Howard M. Bloom

U.S. DEPARTMENT OF COMMERCE Technology Administration National Institute of Standards and Technology

Gaithersburg, MD 20899

$-Q C$

100

.056

NIT

非 5148

1993 



\section{Strategic Plan for the Factory Automation Systems Division}

Howard M. Bloom

U.S. DEPARTMENT OF COMMERCE Technology Administration

National Institute of Standards and Technology

Gaithersburg, MD 20899

March 1993

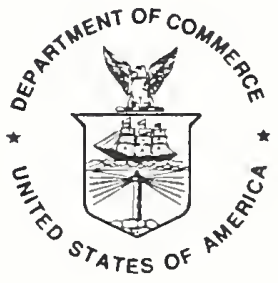

U.S. DEPARTMENT OF COMMERCE Ronald H. Brown, Secretary

NATIONAL INSTITUTE OF STANDARDS AND TECHNOLOGY

Raymond G. Kammer, Acting Director 

Abstract

Executive Summary

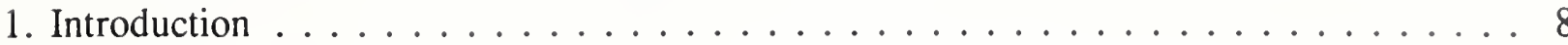

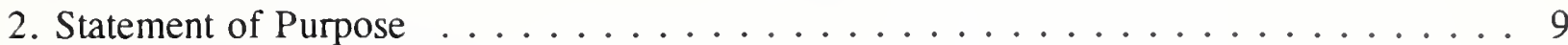

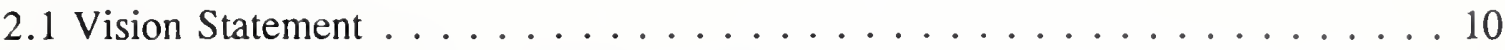

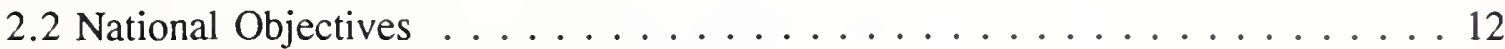

2.3 National Standards Issues . . . . . . . . . . . . . . 13

2.4 A Standards and Technology Strategy .................... 14

3. State of CIM Technology and Standards in FY92 . . . . . . . . . . . . . . . 14

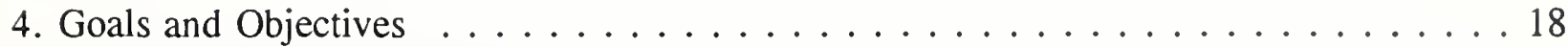

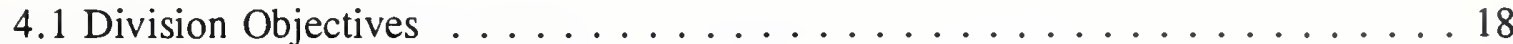

4.2 Critical Success Factors .......................... 19

5. Program Elements ... . . . . . . . . . . . . . . . . 20

5.2.1 Automated Manufacturing Research Facility ........... 21

5.2 .2 National PDES Testbed . . . . . . . . . . . . . . 23

5.3 Project Summaries for FY93 . . . . . . . . . . . . . . . 26

5.4 Long Term Program Objectives (FY94 - FY98) . . . . . . . . . . . . . . 30

5.4 .1 Approach/Technical Plan ...................... 30

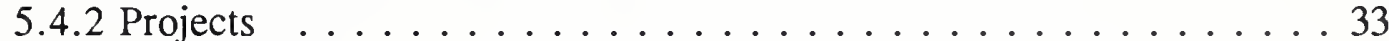

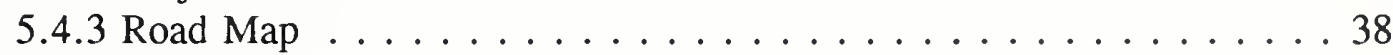

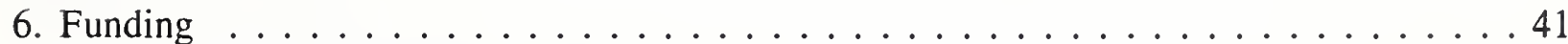

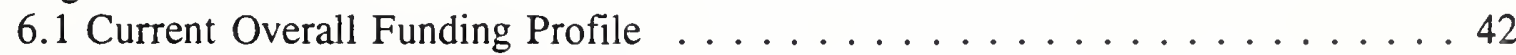

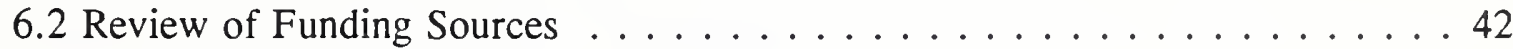

6.3 Plan to Increase Resources (e.g. Business Development Plan) . . . . . . . 43

6.4 Budget Expectations . . . . . . . . . . . . . . . . . . 44

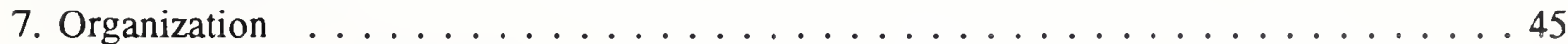

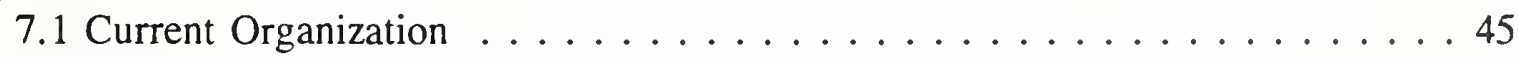

7.2 Human Resource Needs for the Future . . . . . . . . . . . . . 46

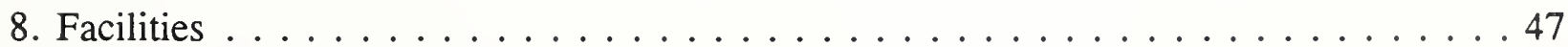

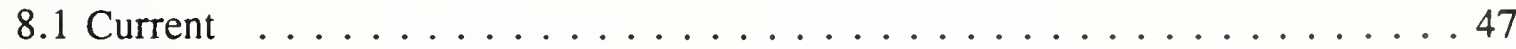

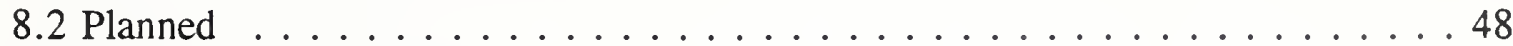

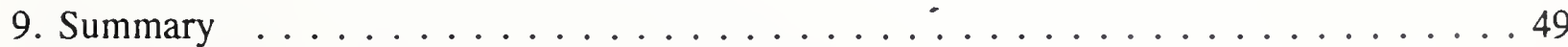


10. Acknowledgement

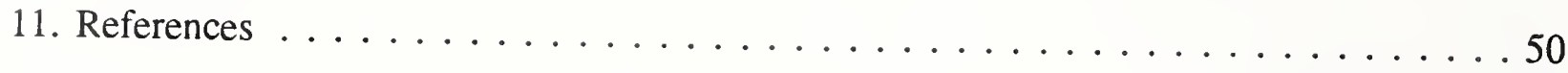




\title{
Strategic Plan for \\ the Factory Automation Systems Division
}

\section{by Howard Bloom}

\begin{abstract}
Abst ract
The objective of this report is to present the strategic plan for the Factory Automation Systems Division. The explosion of new information technologies and new manufacturing methods such as concurrent engineering, with the corresponding requirements for data interface standards, has made it clear that the Division must re-evaluate its present status and develop a strategy that will bring the Division's research and development activities in line with the future needs of U.S. industry.

A vision of 21 st century manufacturing is presented in terms of the implementation of the "Virtual Enterprise" and the use of Multi-Enterprise Concurrent Engineering. The vision is based on reports published by the National Critical Technologies Panel, the Agile Manufacturing Forum, and the government Advanced Manufacturing (AM) and High Performance Computing and Communications (HPCC) Initiatives. All the reports emphasize the need for research into "Integrated Tools for Product, Process and Enterprise Design (as related to advanced manufacturing") and the need for "application of computing and networking to manufacturing (as related in the HPCC")

An environmental assessment is made of the Flexible Computer Integrated Manufacturing and Systems Management technologies. The goals and objectives of the Division are stated in terms of these technologies. The programs in the Division are described and the long term program objectives are given. Plans for additional funding, resources, and facilities are given in terms of program requirements.
\end{abstract}

Key Words: CIM, concurrent engineering, design methods, enterprise integration, interface standards, product data sharing, strategic plan, systems integration

\section{Executive Summary}

This strategic plan will be given to the participants for a workshop that the Division will hold in the summer of FY93 in which key industry, university, government and standards "customers" will be invited.

The following are the highlights of the plan:

Vision - The future manufacturing environment involves creating the framework to support the "virtual enterprise." Independent enterprises are integrated by an information network into an effective system. Within each of these enterprises the various product-related functions and 
product life cycle stages are integrated through the sharing of product and process data, although each stage maintains its own view of the product.

This vision is built upon the concept of concurrent engineering and the conclusions of three important reports:

o Concurrent Engineering methodology is the technical solution to breaking the barriers between organizational units of companies and between companies. This will allow for the effective integration of product and process development required to produce world class products.

o The National Critical Technologies Panel [NCTP91] identified Flexible Computer Integrated Manufacturing (FCIM) and Systems Management Technology (SMT) as key technologies required for Concurrent Engineering.

o The Agile Manufacturing Forum (consisting of key U.S. industry leaders) developed a vision for 21 st century manufacturing [AM92]. There are specific roles for NIST that relate to technology and standards development.

o The Federal Coordination Committee for Science, Engineering and Technology (FCCSET) Advanced Manufacturing Initiative [AMI92] identifies a key thrust in the area of "Integrated Tools for Product, Process and Enterprise Design." Another FCCSET initiative, High Performance Computing and Communications (HPCC) identifies a key thrust in the area of "Technologies for Systems Integration". Both these initiatives and thrusts demonstrate the need to apply information technology to advanced manufacturing systems.

These initiatives, along with the Department of Defense's Critical Technologies Plan [DCTP91], define a set of objectives in the areas of Flexible Computer Integrated Manufacturing (FCIM) and Systems Management Technologies (SMT) that will enable the vision of the 21 st century manufacturing in the United States to be realized. These objectives have been organized around five key technologies:

o Enterprise Integration - Develop enterprise software tools that make use of manufacturing process knowledge to promote integration concepts that apply across entire industry sectors.

o Product Data Exchange - Implement standards-based application protocols for data exchange across manufacturing processes.

o FCIM processes - Promote programs to understand the science of key generic manufacturing processes, with special emphasis on extending design across the product life cycle. 
o Communications and Networking - Demonstrate a robust integrated manufacturing environment with a distributed network utilizing network protocols to transfer data.

o Database and Database Management - Develop FCIM data models and establish fully integrated product databases.

Technology innovation is not the only requirement to meet our vision for 21 st century manufacturing. Standards are needed to facilitate economic interactions that require a high level of cooperation and coordination. Standards are essential due to our growing reliance on technology. However, the growing pace of technological change drives the need for accelerating the development of standards. The Office of Technology Assessment issued a report [OTA92] that focused on how U.S. standards and standards development processes affect U.S. trade and listed several finding relevant to the concept of standards and competitiveness.

A Standards and Technology Strategy will develop new approaches to the implementation of standards that significantly accelerate the standards approval process. Program initiatives need to be developed that analyze the life cycle development of standards and implement tools and procedures that accelerate the availability of standards.

State of CIM Technology and Standards in FY92 - At the present time, implementing CIM in a company requires a tremendous effort to develop software translators for the different applications and databases. If CIM is to be effective, internationally agreed-upon interface standards are necessary to avoid huge translation costs. The European Economic Community produced a Directory of European Standardization Requirements for Advanced Manufacturing Technology [ETSI90] that lists the required standards in terms of seven classifications.

CIM software systems of the future will be "plug compatible" with any system in an enterprise based on the emerging standards described in this report. Applications will have standard interfaces to database systems through standard communication protocols. All applications will be able to exchange product data through the use of a standard product data exchange structure. Software systems will be written using programming languages that exist in a standard operating systems framework (such as POSIX, an emerging international standard based on UNIX) that allows for total portability of applications and data among computer systems.

The National Critical Technologies Panel report [NCTP91] stated that the use of FCIM systems in U.S. industry is not yet widespread. The premise of this strategic plan is that data interface standards are necessary to effectively implement FCIM.

Goals and Objectives - The goal of the Division is to assist industry in producing the technology and standards required to satisfy the vision for U.S. manufacturing in the 21 st century. The Division will make use of a new facility known as the "Advanced Manufacturing Systems and Networking Testbed" (AMSANT). This facility would be used to implement the objectives of the HPCC and Advanced Manufacturing Initiatives. The purposes of the facility are the following: 
o Perform research and development into advanced manufacturing systems and networking.

o Test and develop computer software, manufacturing systems, and systems integration necessary for the successful operation within the U.S. manufacturing community.

o Assist industry to implement voluntary consensus standards relevant to CIM, including standards for networking, electronic data interchange, and digital product data sharing.

o Make high-performance computing and networking technologies an integral part of design and production of products.

o Conduct research to identify and overcome technical barriers to the successful and costeffective operation of advanced manufacturing systems and networks.

o Facilitate industry efforts to develop and test new applications of advanced manufacturing systems and networks.

o Involve both companies which develop manufacturing systems and those that use those systems.

o Provide training for industry on the effective use of these new technologies.

o Work with private industry to develop standards for the use of advanced computerbased training systems, including multimedia and interactive learning technologies, that will accelerate the efficient use of the advanced manufacturing systems.

o Provide mechanisms for the exchange of information about advanced manufacturing systems and networking.

In order to achieve the long term goals of the Division that would be realized through the new Advance Manufacturing Systems and Networking Testbed (AMSANT) Facility, the following are the critical success factors: Department of Commerce support for a new program in Advanced Manufacturing Systems and Networking, effective use of the AMSANT facility, participation in the Advanced Technology Program (ATP), participation in the Manufacturing Technology Centers (MTC) Program, interaction with other government agencies and universities, support for national and international standards activities, interaction with such international programs as European Strategic Program in Research in Information Technology (ESPRIT) and capability to provide information dissemination.

Division Overview - Over the last ten years the Division has been performing most of its research under two major projects: the Automated Manufacturing Research Facility (AMRF) and 
the National PDES ${ }^{1}$ Testbed (NPT).

Through the AMRF [BLOO83], the Division has build up world class capability in a broad spectrum of information technologies related to factory networking, distributed database systems, object methodology, artificial intelligence, data-driven manufacturing, and control systems. Specific manufacturing systems include design, process planning, scheduling, shop floor control, and inspection.

Through the NPT [BLOO89], the Division has worked on key projects such as Application Protocol (AP) Framework and Methodology, Configuration Management of Standards, Validation Testing, STEP Implementation Tools, AP for Inspection Planning, and PDES for Apparel.

The Division has established a strong relationship with standards bodies, industry through cooperative research and development agreements (CRDAs), and universities through project coordination.

Long Term Program Objective - The long term program objective for the Division is to produce the technology and standards required to satisfy the vision for U.S. manufacturing in the 21 st century. There is a unique role that the Factory Automation Systems Division (FASD) plays that makes this objective different from other organization's. FASD has established a special relationship with standards organizations, R \& D institutions, other government agencies, industry end-users, and vendors. FASD works with its partners by providing testing methodologies, integration technologies, and feasibility demonstrations in support of the development of standards, technologies, and world class products.

In order to meet the requirements of the industrial community for advanced manufacturing systems and networking, a new paradigm has been developed to define the type of projects initiated by the Division. This paradigm consists of four major elements: (a) develop required standards, (b) produce the testing and evaluation methods to ensure that quality standards are developed and implemented by vendors, (c) perform research and development into the technologies required to develop the standards and implement the advanced manufacturing systems that conform to the standards, and (d) work with pilot facilities in implementing the FCIM standards through the involvement of FCIM vendors. This paradigm would be implemented through the AMSANT facility which will allow for a broad range of manufacturing data interface standards related to FCIM to be developed.

The following projects (grouped by FCIM/SMT technology areas) are typical examples of the type of research that would take place in the AMSANT facility:

\footnotetext{
'PDES is the commonly used acronym for Product Data Exchange Using STEP. PDES contains an acronym within itself. STEP is the acronym fro standard for the Exchange of Product Model Data.
} 
o Enterprise Integration - factory engineering, integration frameworks, modeling engineering data, process and production management data interchange.

o Product Data Exchange - knowledge-based STEP implementation, application protocol development environment, STEP testing methods and tools, STEP technology development, harmonization of STEP with related standards, application protocol development.

o FCIM Processes - concurrent design, design engineering, tolerancing theory and technology, fault-tolerant systems, intelligent systems, automated equipment program generation, design knowledge representation.

o Communications and Networking - open distributed processing, information integration, electronic library services.

o Database and Database Management - information modeling, shared database for STEP applications, national repository for design and planning knowledge.

To meet the HPCC national objectives for advanced manufacturing and networking, FASD will have to develop a plan that includes the active participation of a broad spectrum of organizations. The major contributions of the Division will be in the area of the development and implementation of the technologies required for the manufacturing data interface standards. The development of the advanced manufacturing and communications technologies will be the primary responsibility of the industrial (and government laboratories within Department of Defense and Department of Energy) and academic research communities with a supporting role from FASD. A strawman for a five year master schedule is presented in this report.

Funding - For the past several years, the Division budget has remained at approximately the $\$ 7.5 \mathrm{M}$ level. Approximately $70 \%$ of this funding is from other agencies to support programs unique to their needs. Approximately $50 \%$ of the overall Division budget is in the area of product data exchange.

The following steps will be taken to implement a plan to increase the resources for the Division:

o Develop a supportive "customer base" in industry.

o Develop a new program initiative to submit to Congress.

o Implement a new facility known as AMSANT.

o Develop an integrated plan for the Division's activities.

o Work with industry to encourage more ATP proposals in Division's areas.

o Maintain the Division's visibility in external activities.

o Increase level of collaboration with industry as means of improving technology transfer.

o Increase level of collaboration with other Divisions at NIST.

o Increase level of collaboration with other government research laboratories. 
To operate a program that addresses the national objectives for implementing FCIM and SMT technologies will require a budget of $\$ 12 \mathrm{M}$ for the Division.

Organization - The Division is located within the Manufacturing Engineering Laboratory (MEL), which is one of the eight technical laboratories at NIST. In addition to FASD, there are four other Divisions in MEL: Automated Production Technology, Fabrication Technology, Precision Engineering, and Robot Systems. There are two offices: Manufacturing Programs and Industrial Relations.

The Division has a total staff of 55 that fall into the following categories: Technical Professionals - 42, Support - 8, Administrative - 2, and Technicians - 3. There are presently 5 supervisors - Division chief, deputy division chief, and three group leaders. There are nine top government-level professionals.

At the current time, there are three groups in the Division: Production Management Systems, Product Data Engineering, and Machine Intelligence. There is one program office: Standards Administrative Office (in support of product data exchange.)

The following steps will be necessary if the Division is to be able to take a leadership role in the implementation of the technologies and standards required to support the FCIM and SMT national objectives:

o Reorganize the groups within the Division to correspond to the major technical areas within FCIM and SMT.

o Provide effective leadership in Division's programs.

o For each of the objectives, develop the skills for implementing these objectives.

o Reorganize the office(s) within the Division to be responsive to the needs of national and international standards issues.

o Provide effective facility management.

In order to meet the resource objectives, the following goals need to be achieved:

o The size of the Division needs to be increased by $33 \%$ in order to properly staff the expected number of groups and offices.

o The number of $\mathrm{PhDs}$ needs to be greatly increased to reach the NIST ratio level of PhDs to technical staff (i.e. 33\%).

o The number of supervisors needs to be increased to handle the expected number of groups and offices.

o Facility managers need to be recruited as the facilities are put in place.

Facility - At the current time, the Division makes use of a variety of facilities in carrying out its research. The following is a list of the facilities grouped under the FCIM/SMT categories:

o Enterprise Integration - Computer-Aided Factory Engineering (CAFE) laboratory. 
o Product Data Exchange - The National PDES Testbed (NPT).

o FCIM Processes - The Rapid Response Manufacturing Facility (RRMF), The Process Planning Testbed, The Design Laboratory, The Algorithm Testing System (ATS) Laboratory

The following steps should be taken for implementing the additional facilities that address issues identified in the FCCSET Advanced Manufacturing "Integrated Tools for Product, Process and Enterprise Design", and the HPCC "Technologies for Systems Integration":

o Develop an architecture for the AMSANT Facility.

o Based on the overall facility requirements, define a set of testbeds with different functionality.

o Prioritize the order in which the facilities need to be developed.

o Construct facilities as projects are initialized.

Summary - The FCCSET thrust in "Integrated Tools for Product, Process and Enterprise Design" and the thrust in "Technologies for Systems Integration" along with the data interface standards will allow for the effective integration of the product and process development required to implement the enterprise framework for producing world class products. The concept of developing technical standards before the commercialization of the associated products will take hold of the U.S. industrial community. The world community realizes the importance of objective technical standards such as those embodied in manufacturing data interface standards and is putting more pressure on the international standards efforts to approve standards quickly so that international concurrent engineering process needs can be met.

\section{Introduction}

The objective of this report is to present a strawman strategic plan for the Factory Automation Systems Division. The explosion of new information technologies and new manufacturing methods such as concurrent engineering, with the corresponding requirements for data interface standards, has made it clear that the Division should reevaluate its present status and develop a strategy that will bring the Division's research and development activities in line with the future needs of U.S. industry.

This strategic plan will be given to the participants for a workshop that the Division will hold in the summer of FY93 in which key industry, university, government and standards "customers" will be invited. The purpose of the workshop will be to better define and articulate the Division's role in meeting the needs of industry now and in the future. The participants will be asked to review and prioritize industrial concerns. Using the strategic plan as a strawman, the workshop will provide the opportunity for the Division to join with industry in various endeavors which will enhance industry's ability to do its job. 


\section{Statement of Purpose}

The manufacturing vision statement described in this strategic plan is based upon a number of government funded studies that address the future needs of U.S. industry. These reports include studies by the National Critical Technologies Panel, the Agile Manufacturing Forum, and the government's new Advanced Manufacturing (AM) and High Performance Computing and Communications (HPCC) initiatives.

In order to understand the vision, it is important to define the key technologies required to support its implementation. A "Critical Technologies" report has been published which identifies key technologies considered essential for the United States to develop in the interests of the Nation's long-term security and economic prosperity [NCTP91]. For the 21st Century Manufacturing Vision, there are two specific technologies mentioned: Flexible Computer Integrated Manufacturing (FCIM) and Systems Management Technologies (SMT). The report defines FCIM as the "integration of product, process, and manufacturing management information into a single interactive network, greatly reducing the number of transactions necessary to product a product." The reason given for selecting FCIM as a critical technology is that FCIM provides the capability for "just in time" manufacturing by allowing new manufacturing systems to be implemented that can respond quickly to product and demand changes. The report defines SMT as a management approach to the integration of the diverse functions carried out by a manufacturing enterprise. Information technologies are viewed as fundamental enablers of advance systems management concepts. The reason given for selecting SMT is that this technology provides industry with the tools to focus on such concepts as "management of change" and "management of technology."

The report "21st Century Manufacturing Enterprise Strategy - An Industry-Led View" was developed under Department of Defense funding to develop a vision of what 21 st century manufacturing will require [AM92]. It states that "a new competitive environment for industrial products and services is emerging and is forcing a change in manufacturing. Competitive advantage in the new system will belong to agile manufacturing enterprises, capable of responding rapidly to demand for high quality, highly customized, products. Agility requires integrating flexible technologies of production with a skill base of a knowledgeable work force, and with flexible management structures that stimulate cooperative initiatives within and between firms." The major finding of the report is that there is a common infrastructure for all agile manufacturing enterprises. The report also identified several key roles for NIST: (1) Lead in articulating benefits of agile manufacturing, (2) Increased participation in developing information and communication systems, (3) Leadership in national and international standards, and (4) Significant funding for R\&D in concurrency subsystems such as distributed databases, enterprise integration, simulation and modeling, data representation, standards, groupware, and others.

The Federal Coordinating Council for Science, Engineering, and Technology (FCCSET) has prepared an Advanced Manufacturing Initiative (AMI), proposal for FY94 [AMI92]. One specific thrust area -- Integrated Tools for Product, Process and Enterprise Design -- will provide the mechanisms for the effective implementation of the Agile Manufacturing Enterprise 
described above. The thrust was defined as follows: "Computer-based hardware and software tools for production design have the same potential for revolutionizing manufacturing as computer aided design and engineering tools have done for product design in the past decade. The overall objective of this thrust is to lower manufacturing costs, reduce delivery times and improve product quality through the coordinated development and use of advanced tools that are being developed by industry, academia and a number of government agencies." A second FCCSET initiative is called "Manufacturing Applications in High Performance Computing and Communications." The emphasis from both initiatives would be placed on providing an integrated framework, operating environment, common databases, and interface standards for a wide variety of emerging tools and techniques for designing manufacturing processes, equipment and enterprises, as well as tools for evaluating the producibility of product designs.

The Agile Manufacturing Enterprise and its technology enabler -- Integrated Tools for Product, Process and Enterprise Design -- will be dependent on both FCIM and SMT. FCIM affects all manufacturing functions including product engineering and design, process planning, production scheduling, subcontractor and vendor activities, part production and product assembly, inspection, and customer service. Tools and technologies that utilize FCIM include Simulation Tools, Computer-Aide Design (CAD), Computer-Aided Engineering (CAE), Group Technology (GT), Computer Aided Process Planning (CAPP), and Factory Scheduling Tools. This is key to efficient production in today's rapidly changing marketplace. SMT includes such technologies as: product data exchange tools (i.e. STEP - Standard for the Exchange of Product Model Data), databases (customized tools for managing and controlling CIM), data-driven manufacturing information systems (storage and retrieval of designs, inventories, and machine capability), and interoperable information systems (i.e. enterprise integration frameworks). SMT is needed for the successful application of concurrent engineering.

\subsection{Vision Statement}

The vision of the future manufacturing environment (see Figure 1) involves creating the framework to support the "virtual enterprise." Independent enterprises operating as suppliers, system integrators, merchants and customers are integrated by an information network into an effective system. Within each of these enterprises the various product-related functions and product life cycle stages are integrated through the sharing of product and process data, although each stage maintains its own view of the product. Based upon standards, the inter- and intraenterprise framework enables the integration of the product life-cycle processes such as design, manufacturing, marketing, maintenance, and improvement. This is commonly referred to as the practice of multi-enterprise concurrent engineering through which the characteristics of world class products are achieved. These characteristics are short-time-to-market, low cost, high quality, and high functionality. 


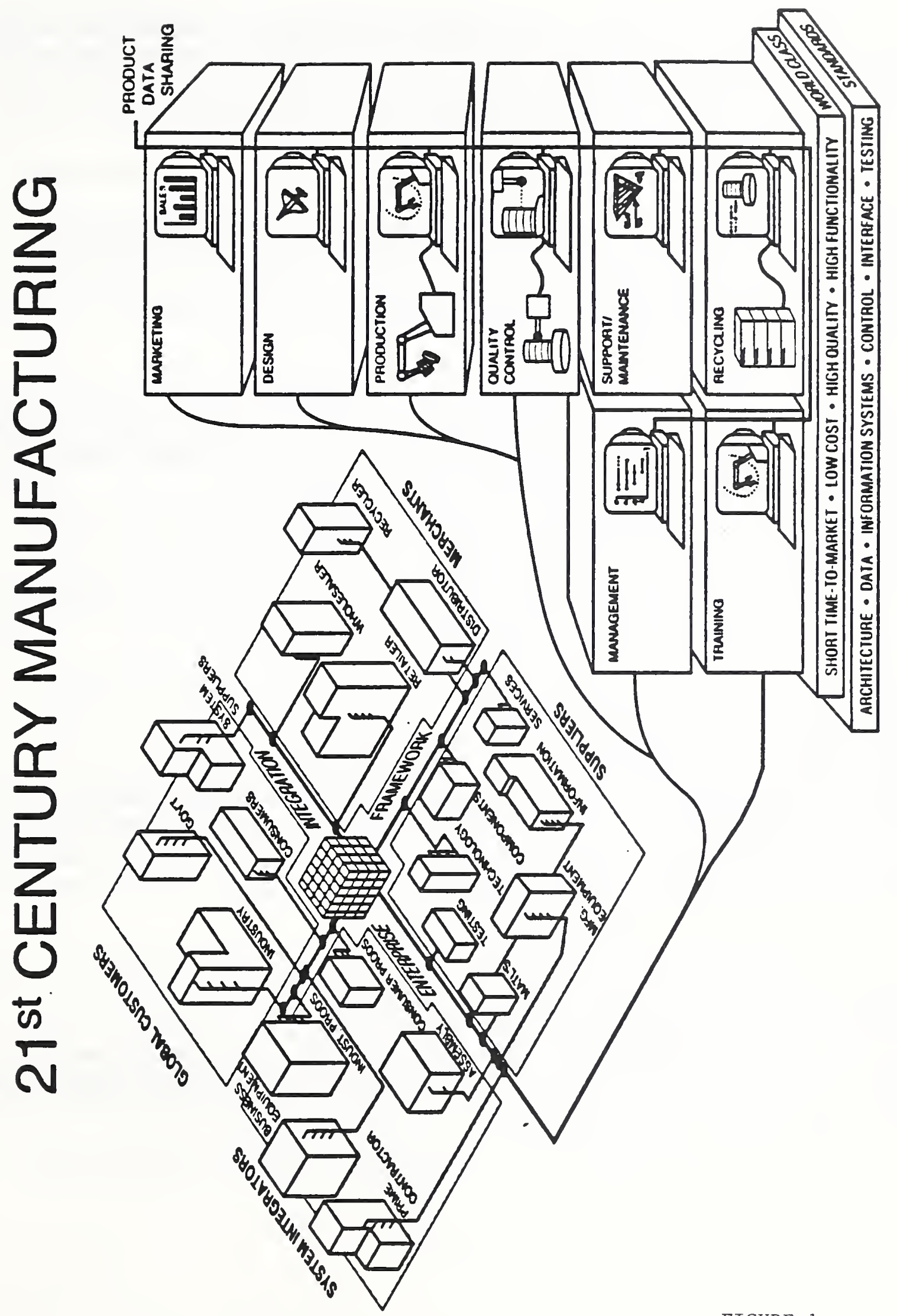

FIGURE 1 


\subsection{National Objectives}

The reports described in the above section along with the Department of Defense's Critical Technologies Plan [DCTP91] define a set of objectives in the areas of FCIM and SMT that will enable the vision of the 21 st century manufacturing in the United States to be realized. These objectives have been categorized under the following five techology areas:

\section{Enterprise Integration}

o Employ a total systems approach to identify and develop enterprise software tools.

o Make available manufacturing process knowledge and computers able to simulate and model the entire manufacturing process.

o Promote integration concepts across entire industry sectors.

\section{Product Data Exchange}

- Initiate a major standards-based application protocol data exchange effort targeted at manufacturing to alleviate the lack of data exchange capability among computer-aided activities (e.g. Computer Aided Design, Computer Aided Process Planning).

o Promote wide use of standard product data that is fully implemented at all levels of design and manufacturing.

o Make available testing methodologies for vendor implementations.

\section{FCIM Processes}

o Promote programs to understand the science of key generic manufacturing processes.

o Develop new design tools and algorithms.

o Extend design to the entire product life cycle.

o Develop modular, flexible, reconfigurable, affordable production processes.

o Develop modular product designs incorporating reconfigurability and upgradability.

o Apply integrated design architecture and product data to shop floor control, including collaborative design, knowledge base concepts for engineering design and manufacturing, use of design tools, and next generation controllers.

\section{Communications and Networking}

o Develop fully distributed network serving enterprise.

o Demonstrate robust integrated manufacturing environment.

o Establish a national, publicly accessible and interactive broadband communications network. o Obtain and share information quickly and link information directly to the production processes. o Implement seamless networking in the industrial base utilizing network protocols to transfer data between customers and contractors. 


\section{Database and Database Management}

o Develop database models to support FCIM functions.

o Define generic database for enterprise integration.

o Establish fully integrated product databases for design, procurement, manufacturing, training, and administrative functions that utilize an industry standard distributed object-oriented database, enterprise integration framework, and database modeling.

\subsection{National Standards Issues}

Technology innovation is not the only requirement to meet our vision for 21 st century manufacturing. Standards are needed to facilitate economic interactions that require a high level of cooperation and coordination. Standards also help to determine the efficiency and effectiveness of the economy as well as the cost, quality and availability of products.

However, governments are using standards to protect their domestic markets and to develop new international ones, to the detriment of U.S. trade. In particular, the harmonization of European standards, which will be completed in 1993, will not only make it harder for U.S. companies to trade in Europe, but will allow the Europeans to take the lead in setting international standards.

Standards have become more important due to our growing reliance on technology. The growing pace of technological change also drives the need for standards. The faster the advance of technologies, the greater the risk in $\mathrm{R} \& \mathrm{D}$ and product development. In fact, it is now necessary to develop standards even before the actual products are made available to the customer.

In the 21 st century, the concept of developing technical standards before the commercialization of the associated products will take hold of the U.S. industrial community. Technology advances will occur so rapidly that the previous standards activities can not keep up with the demand for technical standards. The world community will realize the importance of objective technical standards such as those embodied in product data exchange standards and enterprise frameworks and will put more pressure on the international standards efforts to approve standards quickly so that international concurrent engineering process needs can be met.

The report "Global Standards: Building Blocks for the Future" [OTA92] focuses on how U.S standards and standards development processes might affect U.S. trade. There are many questions addressed in the report but the one of particular interest is "whether and to what extent does the U.S. standards process support the growth and competitiveness of the U.S. economy in a rapidly changing global environment." There were several findings of importance to the concept of standards and competitiveness:

o A growing national stake in standards issues

o Need for greater attention to standards 
o Need for cooperation rather than conflict among U.S. standards bodies

o Need to strike a more appropriate balance between the public and private sectors

o Inadequate federal coordination and policy making

o Need for greater attention to how other governments use standards to create markets for their nations' industries

The report also describes how the U.S. and other countries are rapidly evolving into information-based, knowledge societies, where the creation, use, and communication of information plays a central role. It is more and more being treated a commodity to be bought and sold in the marketplace. This trend will greatly affect standards development. Information can be used to improve the overall efficiency of the production process itself. This growing importance is evident from the continued growth of the information sector of the economy.

\subsection{A Standards and Technology Strategy}

Flexible Computer Integrated Manufacturing with all its associated technologies has clearly been identified as a critical technology in making U.S. industry more competitive internationally. Standards have also been identified as key enablers in the development of the "virtual enterprise" which allows for the broad base of U.S. companies to work together in producing world class products. The question is why hasn't industry been more involved in adopting standards in their activities.

The reason why industry has been slow to adopt standards is because of the slowness in which the standards community can react to approving standards through the consensus process. The information technology described in this chapter (e.g. Integrated Tools for Product, Process, and Enterprise Design) is evolving so rapidly that companies prefer to purchase the latest products in the belief that they will provide a technology edge over their competitors. Obviously these products are not based on standards that cannot be approved in an acceptable time frame.

The answer to this problem is to develop new approaches to the implementation of standards that significantly accelerate the standards approval process. Program initiatives need to be developed that analyze the life cycle development of standards and implement tools and procedures that accelerate the availability of standards. The future will involve the concurrent development of new technology and corresponding standards that allow vendors to build products to meet the technology needs.

\section{State of CIM Technology and Standards in FY92}

The present state of software associated with the implementation of CIM architecture is discussed. Emphasis is placed on the need for the implementation of standards that will facilitate the integration of the software into a cost-effective CIM environment. 


\section{Production Management Systems}

Production management systems are divided into three major areas: manufacturing data preparation, shop-floor control, and administrative management.

For manufacturing data preparation, there is a broad range of software products that provide capabilities that are usually dependent on the product type (i.e., mechanical vs. electrical products). The CAD system used for mechanical design is usually quite different than the system used for electronic design and relies on different analysis tools to generate an efficient product design. This is mainly due to the inherent 2-D nature of electronics and the 3-D nature of mechanical parts. CAPP systems are mostly interactive with the user participating in the generation of the plans. There are several programs presently available that employ "expert systems" that allow for the automatic generation of process plans, but these programs usually require an intensive initial effort to identify the rules that will be used for specific part families. Although CAD and CAPP systems were originally mainly available on mainframes, today they are almost exclusively implemented on either engineering work stations or personal computers (except in industries such as aerospace where large mainframes are a way of life). Today's data preparation systems will be changing rapidly as the emerging standard, STEP (Standard for the Exchange of Product Model Data), becomes mature [SMIT88]. STEP is the international standards effort (officially entitled ISO 10303) to develop a mechanism (independent of a given commercial system) capable of completely representing product data throughout the life cycle of a product. The completeness of this representation makes it suitable not only for neutral file exchange, but also as a basis for implementing and sharing databases and archiving.

The basic strategy of the STEP community is to create a set of "application protocols (APs)" that convert end-user requirements into specifications that can be used to test conformance of vendor implemented application software (i.e. configuration control of design data) to the standard. An application protocol is an actual standards document that contains the following types of information: definition of the scope (using an activity model), description of the information to be exchanged from the end-user's viewpoint (using an information model containing data elements that the end user commonly uses), description of the information to be exchanged from the STEP viewpoint (using an information model containing data elements that are taken from a collection of resource models using STEP terminology), and a users guide for implementing the application. A corresponding document to the AP will specify the means of testing (using test suites).

The first version of STEP reached Draft International Standard status in February, 1993. There was one AP included in this initial release - "Configuration Control of Design Data." Another AP, "Explicit Draughting" , will be issued within the next few months. In the years to come, there are APs scheduled to increase the mechanical parts capability, and then introduce capabilities in such products as electronics, apparel, construction, sheet metal, and other areas.

For shop-floor control systems there are many programs available for performing job scheduling and controlling shop operations. However, there is not an effective link between shop-floor 
control and administrative management systems. This has resulted in the need to have software translators to convert the output of process planning systems and NC programming systems into the actual input used to drive the machines on the shop floor. Research efforts have been involved in developing a true "data driven" production environment, but this will ultimately require changes in the machine control architectures (as in the Next Generation Controller Project underway by the U.S. Air Force Manufacturing Technology Program). In fact, future shop floor control systems will be driven by product data (e.g. STEP) that will eliminate the need for much of the intermediate software translations that are presently required [BLOO89].

Administrative management systems have been automated long before the manufacturing-related systems. The computer programs are usually developed for large mainframe computers (although today these systems are available on personal computers). They are often obtained as an integrated set from a single software vendor where the database integration comes with the programs. Historically there has been little interaction between the manufacturing software developers and the business systems developers. It is for this reason that CIM has been very difficult to implement [FOSS90]. However, there are now efforts underway in enterprise integration that deal with the model of the entire enterprise.

\section{Data Management}

For data management there are several modeling techniques now available (as software products) that allow the representation of the real-world objects, as well as the information units that describe and distinguish them. An example of a public domain modeling technique is IDEF1, which has been used both in the manufacturing database environment, as well as in the standards community for STEP [IDEF81]. It is an extremely complex effort to integrate all the information used by CIM applications [SCHE89], but a necessity, if an enterprise wants a successful CIM environment.

For data administration there are many software database systems available today, some that allow only for a centralized access to shared data among the CIM processes and some that allow for a distributed access to the CIM data. Some of the database systems allow the applications that access the database to interact through a "data dictionary" which defines all the data and their interrelationships. In most cases, this means that the CIM database can be restructured without all the applications being revised.

Today's software systems are already making use of such standards as SQL (Standard Query Language), IRDS (Information Resource Dictionary System), and RDA (Remote Data Access) in order to offer complete data administration capability for CIM [BLOO88]. By using this open database architecture approach, the CIM application software vendors can produce software independent of the actual physical means of accessing the information that is required by the application. 


\section{Communication Management}

The communications software that is available today falls into two categories: closed system and open systems. The closed systems are those which rely only on products from a specific computer vendor. The open systems are those that adhere to the Open Systems Interconnection (OSI) network architecture [WEST88]. Specific applications within the OSI framework include the Manufacturing Automation Protocols (MAP) concept of one physical bus connecting all factory-floor stations, and the Technical Office Protocols (TOP) used for connecting engineering work stations. In particular, there is the Manufacturing Message Specification (MMS) which provides the level of message handling support required at the specific device to be connected to the network.

\section{Standards Issues}

At the present time, implementing CIM in a company (or an enterprise that involves an industrial network of partners and subcontractors) requires a tremendous effort to develop software translators for the different applications and databases. If CIM is to be effective, internationally agreed-upon interface standards are necessary to avoid huge translation costs. The European Economic Community produced a Directory of European Standardization Requirements for Advanced Manufacturing Technology [ETSI90] that lists the required standards in terms of seven classifications.

Perhaps the most important standards activity at this time is the work by the International Organization for Standardization (ISO) Technical Committee on Industrial Automation (TC184) Subcommittee on Architecture and Communications (SC5) Working Group on CIM Architecture (WG1) on a framework for modeling CIM [ISO90]. This work is based on the CIM-OSA (CIM Open Systems Architecture) project [AMIC89] which could revolutionize the development of CIM software systems.

In addition, an industry led, government facilitated National Initiative for Product Data Exchange (NIPDE) has initiated a program to accelerate and coordinate research, standards development and deployment of systems through the involvement of organizations that contribute to the entire range of PDE activities [NIPD91].

\section{Conclusion}

CIM software systems of the future will be "plug compatible" with any system in an enterprise based on the emerging standards described in this report. Applications will have standard interfaces to database systems through standard communication protocols. All applications will be able to exchange product data through the use of a standard product data exchange structure. Software systems will be written using programming languages that exist in a standard operating systems framework (such as POSIX, an emerging international standard based on UNIX) that allows for total portability of applications and data among computer systems. 
Perhaps the most exciting effort under way is the increased use by companies of "concurrent engineering" methodologies [WINN88]. The research and development now proceeding in design theory and methodology will lead to new ways of integrating the processes that make up a part of the product's life cycle.

In summary, the use of FCIM systems in U.S. industry is not yet widespread [NCTP91]. However, the premise of this strategic plan is that data interface standards will allow industry to effectively implement FCIM.

\section{Goals and Objectives}

The goal of the Division is to produce the technology and standards required to satisfy the vision for U.S. manufacturing in the 21 st century. Under the broad banner of multi-enterprise concurrent engineering, the Division will implement a program that addresses the issues identified in the FCCSET Initiative Advanced Manufacturing thrust "Integrated Tools for Product, Process and Enterprise Design," and the Initiative High Performance Computing and Communications thrust "Technologies for Systems Integration" initiatives. The Division will make use of a new facility known as the "Advanced Manufacturing Systems and Networking Testbed" (AMSANT) to execute this program.

\subsection{Division Objectives}

The objectives of the facility are the following:

o Perform research and development into advanced manufacturing systems and networking.

o Test and develop computer software, manufacturing systems, and systems integration necessary for the successful operation within the U.S. manufacturing community.

o Assist industry to implement voluntary consensus standards relevant to CIM, including standards for networking, electronic data interchange, and digital product data sharing.

o Make high-performance computing and networking technologies an integral part of design and production of products.

o Conduct research to identify and overcome technical barriers to the successful and costeffective operation of advanced manufacturing systems and networks.

o Facilitate industry efforts to develop and test new applications of advanced manufacturing systems and networks.

o Involve both companies which develop manufacturing systems and those that use those systems. 
o Provide training for industry on the effective use of these new technologies.

o Work with private industry to develop standards for the use of advanced computerbased training systems, including multimedia and interactive learning technologies, that will accelerate the efficient use of the advanced manufacturing systems.

o Provide mechanisms for the exchange of information about advanced manufacturing systems and networking.

\subsection{Critical Success Factors}

In order to achieve the goals and objectives of the Division that would be realized through the AMSANT Facility, the following are the critical success factors:

o Increased level of DoC support by the initiation of several new programs in the area of Advanced Manufacturing Systems and Networking. For the FASD, advanced manufacturing systems are defined to be those systems for which information technology is a key element. This would include such systems as design, process planning, scheduling, inspection, off-line programming, and shop floor control.

o Effective use of the AMSANT facility to develop, refine, test, and transfer advanced computer-integrated, electronically-networked manufacturing technologies and associated applications to U.S. industry.

o Increased FASD participation in the Advanced Technology Program by encouraging industrial consortia to submit proposals in areas identified in this report.

o Increased FASD participation with new Manufacturing Technology Centers as they are created.

o Increased level of interaction with other government agencies by supporting their unique technology and standards requirements.

o Increased level of interaction with universities through the use of grants and contracts.

o Increased level of support for national and international standards activities.

o Increased level of interaction with such international programs as ESPRIT (European Strategic Programme for Research in Information Technology) in the area of prenormative research and development of Information Technology for Manufacturing.

o Increased Division capability to provide information dissemination in its key technology areas. This can be accomplished by building on the STEP On-Line Information System (SOLIS) that supports the National PDES Testbed and its management of documents on 
the STEP standard and the related technology.

\section{Program Elements}

As stated earlier (see section 2.2), the long term program objective for the Division is to produce the technology and standards required to satisfy the vision for U.S. manufacturing in the 21 st century. Under the broad banner of multi-enterprise concurrent engineering, the Division will implement a program that addresses the issues identified in the FCCSET Advanced Manufacturing Initiative technical area "Integrated Tools for Product, Process and Enterprise Design" and High Performance Computing and Communications Initiative technical area "Technologies for Systems Integration." The Division will make use of a new facility known as the "Advanced Manufacturing Systems and Networking Testbed" (AMSANT).

This section describes the technology and standards projects in the Division. The section starts with the technical theme that has been used by the Division as a mechanism for deciding on what are appropriate projects for the Division. Next, a brief history of the research and development activities of the Division is presented in order to detail the skills and experience of the staff. Following this background, the FY93 projects are presented under the five key technology categories defined in section 2.2. Finally, the Division's long term objectives are presented in terms of typical projects to be pursued under the five technology categories.

\subsection{Overall Technical Theme}

The Factory Automation Systems Division (FASD) is one of five Divisions within the Manufacturing Engineering Laboratory (MEL) at the National Institute of Standards and Technology (NIST). The MEL programs are organized into five areas: Automated Manufacturing, Precision Engineering, Robotics, Manufacturing Data Interface Standards, and Support for Manufacturing Technology Transfer (see [JACK92] for a detailed description of the major technical programs in the Laboratory).

The mission of the Factory Automation Systems Division (FASD) is to provide a focus for national research and standards efforts related to information systems for manufacturing. To carry out its mission the Division conducts a major research and development program in two of the five MEL program areas: Automated Manufacturing and Manufacturing Data Interface Standards.

In recent years, information technology and information systems have become increasingly important in the manufacturing enterprise. Improved information systems are key elements in refining current manufacturing methods and in creating new technologies to develop products, reduce production costs, shorten commercialization lead times, and raise overall product quality.

The scope of the Division's programs is the application of information technology and associated standards to a multi-enterprise environment [CARV91]. More specifically, the Division's staff members apply the expertise in information technology and their knowledge of manufacturing 
to promote multi-enterprise concurrent engineering in the manufacturing of discrete parts [BLOO92].

\subsection{Brief History of FASD}

The Division started as a small group created to support manufacturing systems integration for the Automated Manufacturing Research Facility (AMRF) that was initiated in 1981 [BLOO83]. The group grew in size and mission as more systems were implemented to support the research activities in the AMRF. Finally, the group became a division in 1984 and took on the scope of information technology in support of advanced manufacturing.

This section summarizes the research conducted by the Division over the last ten years through the mechanism of two key projects: Automated Manufacturing Research Facility (AMRF), and National PDES Testbed (NPT).

\subsubsection{Automated Manufacturing Research Facility}

The AMRF was constructed as a testbed for research in the automation of small batch manufacturing. Construction started in late 1981 and by late 1986, the testbed was made available for selected research in automated manufacturing, The object of the program has been to identify and exercise potential standard interfaces between existing and future components of small batch manufacturing systems and to provide a laboratory for the development of factory floor metrology in an automated environment [BLOO83]. The AMRF has served as a laboratory for collaborative work among all four technical divisions in the Manufacturing Engineering Laboratory. Although the Division's long term objectives involve developing technologies and standards for multi-enterprise concurrent engineering, for the most part, the Division has been working in the area of Computer Integrated Manufacturing (CIM) because of the nature of the AMRF.

The Division was responsible for developing several key CIM technologies:

o Factory Networking - Standards such as the Open Systems Interconnect (OSI) were introduced in the mid 80's and incorporated into the AMRF. Techniques such as "Common Memory" were developed that allowed the AMRF control systems to communicate in real time and share information about the key input/output variables used in the command and status feedback messages. By the end of 1987, the AMRF network architecture had been implemented and remained stable. The network allowed for effective communication across a broad spectrum of computer platforms and manufacturing systems (i.e. robots, machine tools and coordinate measurement machines) [RYBC88].

o Distributed Database Systems - The Integrated Manufacturing Data Administration System (IMDAS) was designed and implemented to allow for the different database systems to communicate and to make the collection of manufacturing control databases appear as one logical database to the AMRF control system applications. The AMRF provided an environment that 
required sharing of data among control, sensory and administrative processes which were invariably distributed over many different computer systems. IMDAS had to address issues associated with diverse computer systems, data systems and databases, real-time data access, and integration of new systems into a running environment. The IMDAS prototype system implementation provided a verification of the methodology developed by the IMDAS team [LIBE88].

o Process Planning - The DAPP (Distributed Automated Process Planning) system was designed to support process planning in a small batch facility where all production operations are under direct computer control. The system consisted of robust interfaces to support both future development of interactive process engineering tools and automated intelligent process planning systems [BROW87]. A process planning language, ALPS (A Language for Process Specification) was developed based on directed graph notation which allows for the full specification of parallel activities, event synchronization, alternative processes, resource management, and task decomposition [CATR91]. Another key research effort within this project resulted in the development of SIPS (Semi-Intelligent Process Selector) which used Artificial Intelligence techniques for generative process selection. SIPS considered a metal part to be a collection of machinable features, and for each feature, it generated a sequence of machining processes to use in creating that feature [NAU87]. An important part of the process planning system was the development of a framework for the design and implementation of process reasoning modules which characterize processes in terms of their effects, constraints, and process parameters [RAY87].

o CAD Directed Machining - The Vertical Workstation was designed to execute numerically controlled (NC) programs generated automatically from a feature-based design of the metal part [KRAM88]. The workstation was routinely used to automatically generate both the NC programs and the robot handling programs required to manufacture a metal part. After the programs were generated, they were automatically downloaded to the equipment controllers which executed the programs immediately.

o Hierarchical Control Systems Emulation - Emulation systems such as the Hierarchical Control System Emulator (HCSE) made it easy to test the performance of the physical systems without actually using the real systems [BLOO84].

o Material Handling - A material handling system consisting of two automatically guided vehicles, tray roller tables, a storage and retrieval system, control computers, and a tender terminal to coordinate manual support services was implemented. This system was developed using the hierarchical control systems architecture [MCLE86].

- CAD Directed Inspection - A feature-based front-end, based on referencing tolerance information back to the part geometry, was designed to automatically generate the inspection plan for inspecting a metal part on a Coordinate Measurement Machine [HOPP84]. This technology was implemented on the Inspection Workstation in the AMRF [MONC88]. 
o Hierarchical Production Control Systems - A five layer hierarchical production control model was developed to manage an automated factory. This model was implemented at both the cell control and workstation control levels within the AMRF [JONE86].

o Manufacturing Data Preparation - This project was concerned with the integration of the functions which generate and update the data needed to drive the AMRF control functions [HOPP87]. It was the research efforts on this project which led to the Division's intensive involvement in the Product Data Sharing standards program.

By the end of FY92, the Division's involvement in the AMRF program has resulted in the following status:

o Skills and Experience - The Division staff had built up world class capability in a broad spectrum of information technology related areas such as: factory networking, distributed database systems, object methodology, artificial intelligence, data-driven manufacturing, and control systems. Specific manufacturing systems knowledge resided in the areas of design, process planning, scheduling, shop floor control, and inspection. However, the facilities available for performing automated manufacturing research were segmented among the various projects, unlike the earlier years when there was only the AMRF available to demonstrate capabilities such as overall systems and data integration.

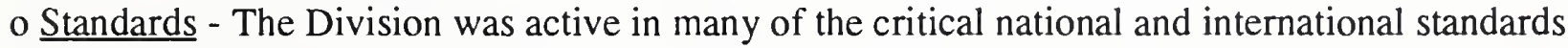
activities associated with the technology areas such as dimensional metrology and information processing.

o External Collaborations - The CRDA (Cooperative Research and Development Agreement) had become the key mechanism for working with industry. The Division had CRDAs (or research associate agreements) with five leading manufacturing companies. In addition, the Division was actively working with several industrial consortia. The Division also had a working arrangement with ESPRIT [ESPR91].

o Availability of New NIST External Programs - The Division was just beginning to realize the potential of the new structure of the NIST Advance Technology Program (ATP) [ATP92]. One specific award was made to the National Center for Manufacturing Sciences (NCMS) for a five year program in Rapid Response Manufacturing (RRM). The program will address key technologies including a manufacturing model that integrates product and process data in a consistent manner, an advanced computer-aided engineering environment, "knowledge-based" software aids for design and process planning, and new production technologies to make products directly from design software.

\subsubsection{National PDES Testbed}

The National PDES Testbed, initiated in 1988, is a focus for planning, coordination, and technical guidance of a national effort for STEP development and implementation [BLOO89]. 
The national effort consists of a growing network of participating organizations of various types. The testbed is comprised of laboratories, computer hardware and software systems, and testing tools. The testbed supports the goals of the IGES/PDES Organization (IPO) and the International Organization for Standardization (ISO) to establish an international standard in product data sharing. Under U.S. Department of Defense Computer-aided Acquisition and Logistic Support (CALS) program funding, the testbed is advancing the development of product data sharing technologies. The overall objective for the testbed is to provide technical leadership and a testing-based foundation for the rapid and complete development of the STEP specification [MCLE90].

The following were the major projects within the testbed during the first five years (upto 1992):

o AP Framework and Methodology - This project involved developing a STEP AP framework for defining, planning, and managing STEP AP projects. This project will also test and refine the basic AP methodology ([PALM92-1] and [PALM92-2]). These two key documents were ready for release into the standards community in FY92.

o Configuration Management Systems and Services - Its objective was to provide an orderly framework within which the development of the STEP standard can take place. The system allows remote users to access documents, software, and test data that has been made publicly available. It also keeps track of different versions of each element of STEP [RESS90]. By the end of FY92 the following capabilities were readily available: STEP On-Line Information Service [KATZ91-1], methodology for configuration management [KATZ91-2], procedures for managing STEP documents [KATZ91-3]), and a mail server to electronically distribute documents [RESS91].

o Testbed Readiness - Its objective was to ensure that the testbed systems are stable, reliable, and able to be used for their intended purpose. The project performs five major activities: tools acceptance testing, database administration, UNIX environment development, testbed training, and testbed hotline [BREE91]. By the end of FY92, there were several different platforms (IBM, DEC, CV, HP, and Sun) being supported and the project had performed several acceptance testing operations for the PDES, Inc block point releases. The latest set of NIST STEP Toolkit and the PDES, Inc. software were available for use by STEP developers.

o Validation Testing - Its objective was to define methodologies for validation testing of application protocols, construct software for AP validation, specify requirements for testing software, define specifications for test cases, and provide a reliable environment for testing APs [MITC90]. By the end of FY92, the methodology for testing application protocols ([MORR91] and [MITC91]) had been developed, and the testing facility with its tools and techniques [MORR92] was operational.

o STEP Implementation Tools - The focus of this project was to develop software tools that enable STEP to be implemented and subsequently used in industry. This project produced software specifications and tools that will help commercial software developers realize systems 
that exchange and share data according to STEP and assist STEP users as they transition to a STEP environment [CLAR91-1]. By the end of FY92, the following capabilities were available: STEP Exchange File Migration Tool [CLAR92-1], FED-X:Express Compiler [CLAR92-3], Express Working Form Implementation [CLAR92-4], Express to SQL translator [MORR90], SQL Database Loader [NICK90], and a new STEP editor - Dataprobe which replaces an earlier editor [CLAR90].

o STEP Production Cell - The objective of this project was to construct a prototype STEP-based manufacturing cell to demonstrate how parts are produced in a STEP environment. A plan was developed for this project [FOWL90] but there was insufficient funding to initiate the actual development activity.

o Product Data Exchange Network - This project was meant to create a network of organizations and individuals dedicated to supporting the specification, validation, prototyping, commercial development, and conversion to STEP. A plan was developed for this project [FREC90] but there was insufficient funding to initiate the actual network activity.

By the end of FY92, the National PDES Testbed had become a mature facility with the following status:

o Availability Technology - Systems existed for performing validation testing of emerging application protocols, a STEP toolkit was being used by developers of STEP models, STEP OnLine Information System (SOLIS) was being used to access and manage STEP documents and software, a framework and methodology existed for application protocol development, and a facility was readily available with a full suite of computer platforms and support software. However, there still was no NIST funding available for supporting the testbed and the existing CALS funding was decreasing yearly and becoming more directed towards specific DoD requirements.

o Standards - The Division was still involved in the overall chairing of both the national (IGES/PDES Organization) and international (International Standardization Organization/Technical Committee 184/SubCommittee 4 - Industrial Data and Global Manufacturing Languages) standards activities. In addition, the staff was heavily involved in many of the working group projects within SC4. In addition NPT staff had responsibility for the overall AP framework and methodology efforts.

o External Collaboration - The Division was closely tied into two major consortia: PDES, Inc. and the American Apparel Manufacturers Association. There were CRDAs (or research associate agreements) with GM/EDS (IPO chairmanship), IBM (STEP development), Industrial Technology Institute (conformance testing), STEP Tools Incorporated (STEP toolkit development), DEC (STEP toolkit development), Versant (STEP-based manufacturing with object-oriented technology), and ModaCad (PDES for Apparel).

o Availability of New NIST External Programs - The Division was actively engaged with the 
NIST Manufacturing Technology Center (MTC) program [MTC92]. With the initiation of the National Initiative for Product Data Exchange (NIPDE), the Division has begun communicating with the Great Lakes Manufacturing Technology Center, operated by the Cleveland Advanced Manufacturing Program (CAMP) in Cleveland, Ohio. CAMP is an active participant in the NIPDE program with key thrusts in the area of STEP testing and training. In addition, the Division has a long-standing relationship with the Industrial Technology Institute (ITI) which manages the Midwest Manufacturing Technology Center at ITI in Ann Arbor, Mich. The Division presently has two active programs (both Navy Mantech supported) with ITI "Conformance Testing Methods and Services" and "Interorganizational use of STEP."

\subsection{Project Summaries for FY93}

The following is the list of key projects in the Division initiated in FY93 or continued from earlier years. They are organized under the five key technologies.

\section{Enterprise Integration}

o Manufacturing Systems Integration (MSI) - This project became the AMRF focus for the Division in FY90. Its goal is to develop a system architecture which incorporates an integrated production planning and control environment and to establish a testbed for production management architectures which integrate process planning, production planning and shop floor control. Accomplishments from this project include a production management information model [RAY92-1], MSI integration architecture [SENE91-1], and a control entity interface specification for controllers [SENE91-2]. By the end of FY92, the MSI project was reaching conclusion with an expected demonstration of the MSI architecture in December 1992. This project is being supported by the Navy Mantech Program.

o Computer-Aided Factory Engineering - This project was just beginning in the FY92 time period. Its objective is to (1) investigate critical issue areas pertaining to engineering factories in the U.S. and (2) identify and develop solutions for computer-aided factory engineering. This project is being supported by the Navy Mantech Program.

o Enterprise Integration Framework - Its objective is to lead international activities aimed at defining and developing a framework and guidelines for applying information technology to improve industrial competitiveness. The key accomplishment was the resulting agreement reached between European Strategic Programme of Research in Information Technology (ESPRIT)'s Computer Integrated Manufacturing and Engineering (CIME) program and the U.S. to define and implement projects within the arena of information systems for manufacturing. These projects are being executed through the participation of U.S. industrial consortia such as PDES, Inc. and Microelectronics Computer Corporation (MCC), and ESPRIT project consortia [ESPR91]. This project is being supported by the Air Force Mantech Program. 


\section{Product Data Exchange}

o IPO/ISO Management - The objective of this project is to provide effective leadership of both the national standards effort (IPO) and the international standards effort (ISO/STEP). The Division has the responsibility for chairing both organizations. The key deliverable in FY93 is to publish the Draft International Standard for the Initial Release of STEP. This project is funded by NIST.

o STEP Requirements Management - The objective of this project is to address tasks required to develop a STEP planning model for CALS, and to establish a formal approach to defining and tracking STEP requirements for DoD and U.S. industry. Key deliverables in FY93 include developing the planning model and specifying the requirements management process. This project is funded by the CALS program.

o Application Protocols for DoD and Industry Requirements - The objective of this project is to develop STEP APs to meet DoD and industry priority requirements. The NPT, in cooperation with designated representatives of DoD and industry will conduct a comprehensive analysis of application protocol requirements. In FY93, an overall plan for an extensible AP suite for technical data packages will be developed and the detailed requirements specification of STEP-based Level 3 (production) technical package will be established. This project is funded by the CALS program.

o Application Protocol Development Environment (APDE) - The objective of this project is to provide a computer integrated systems environment for AP developers to aid in reducing the effort required to develop useful APs. An AP Information Base containing the STEP documents, the STEP standardized information constructs in EXPRESS, AP requirements, and AP test cases will be established to support AP development, interoperability, and re-use of STEP technical components. In FY93, the APDE functional specification will be developed, the APDE architecture specified, and an initial demonstration given of APDE capabilities. This project is funded by the CALS program.

o STEP Implementation Prototypes - The objective of this project is to provide technical support and technology transfer of APDE products and results to AP projects for DoD user environments. Technical support, training, and the APDE facility will be made available to DoD AP teams, PDES Inc., and other users. Assistance will be provided in defining test elements for APs, and for evaluating the AP design to optimize the performance of product data exchange. This project is funded by the CALS program.

o Testing Methodologies and Tools - The objective of this project is to focus on enhancing the quality of the STEP specifications, provide quality management guidelines and processes for APS and resource models, and initiate feedback early in the development cycle for APs. In FY93 a test program for AP validation will be established, and a validation system for EXPRESSbased tools will be developed. This project is funded by the CALS program. 
o Interorganizational Assessment for STEP - The objective of this project is to develop a prototype, user-friendly, computer-based tool which will help assess an organization's state of interorganizational readiness to use STEP based technologies. In FY93, tool requirements will be identified and the final tool will be produced in FY94. This effort is in collaboration with the Industrial Technology Institute. This project is funded by the Navy Mantech program.

o AP for Inspection Planning - The objective of this project is to develop an application protocol for the inspection planning process. A key early effort was to identify the various national and international standards related to tolerancing [FENG92]. The plan for an AP for Inspection Planning has been initiated at both the IPO and ISO. In FY93, work on the Part 47 (Tolerance Model) will be completed and a draft application resource model (ARM) will be developed. This project is in collaboration with the ESPRIT funded program -- Visual Inspection of Mechanical Parts (VIMP). This project is supported by NIST.

o PDES for Apparel - This project is aimed at improving the productivity, quality control, and competitiveness of the U.S. apparel industry by helping to develop methods for product data exchange appropriate to the industry [LEE92]. An apparel pattern information model was developed to demonstrate the feasibility of extending STEP to include the exchange of apparel pattern data [LEE90]. A prototype system was implemented for translating apparel pattern data between different file storage formats [MONC91]. The long range goal is to develop a comprehensive specification for sharing apparel product data throughout the entire product life cycle. This project is supported by Defense Logistics Agency (DLA) Mantech Program.

\section{FCIM Processes}

o Rapid Response Manufacturing - This project was initiated in FY92 as an intermural project through the NIST ATP Office. The principle objective is to establish collaborations with the NCMS RRM consortium and to leverage NIST skills and technologies to ensure the advancement of RRM capabilities. A RRM Testbed Laboratory will be established in FY93 to verify RRM results and identify issues with technology and standards applied to RRM.

o Process Planning Testbed - This project was initiated to encourage open collaborations between process planning researchers, based upon an integrating framework, to allow testing and experimentation of various combinations of planning systems. ALPS, a process specification language developed in the AMRF process planning project, has become a key element in the collaborative process planning testbed research [RAY92-2]. Another aspect of the testbed involved implementing an on-line bibliographic reference system that allows process planner researchers to have ready access to each other's papers. This project is being supported by the Defense Advanced Research Program Agency (DARPA).

o Manufacturing Design Research Testbed - Its objective is to evaluate software tools for integrating design and analysis. An engineering design laboratory was established to study the design process, understand how design information can be represented, and determine how to make design information available to necessary systems throughout a product's life cycle. By 
the end of FY92, a variety of tools had been acquired and installed into the laboratory [FEEN91]. An important deliverable in FY93 is to prototype computer interpretable design knowledge representations. This project is being supported by DARPA.

o CMM Software Performance - Its objective is to develop methods to evaluate the performance of software used in inspection systems. Accomplishments within this project include the publication of current geometric tolerancing theories and CMM inspection data analysis algorithms [FENG91], and the implementation of ATS (Algorithm Testing System) which is a software package for testing geometric fitting software for CMMs [ALGE92]. This project is being supported by the Navy Mantech Program.

o Reverse Engineering for a Production Cell - The objective of this cooperative project between the Naval Aviation Depot at North Island (NADEP NI) and NIST is to design and implement a Reverse Engineering Production System at the NADEP NI facility. This technology will provide NADEP NI with the capability to develop CAD models of replacement parts by optically scanning existing parts to obtain dimensional data. This data will be used to generate NC part programs to manufacture the replacement parts. This project is being supported by the Navy Mantech Program.

o Metal Powder Processing - This project developed a controller for the metal atomization process capable of regulating the production of metal powders and of using acquired knowledge to increase the efficiency of the process [OSEL91]. A key element of this project was the use of neural networks as represented in the Collective Learning Systems Theory which postulates a hierarchical network of cellular automata which acquire their knowledge through learning based on a series of trial-and-error interactions with an evaluating environment [OSEL89]. A key objective in FY93 is to demonstrate a methodology which can be used to automatically generate the strategies necessary to control industrial production processes. This project has been jointly supported by the Materials Science and Engineering Laboratory at NIST and an industrial consortium, and in FY93 the Navy Mantech Program is also funding some of the development work.

o Enhanced Machine Controller - The objective is to develop technologies and standards that will help the U.S. machine tool industry compete in the global marketplace. The project will work to accelerate the development of open architecture machine tool controllers and third-party systems. This is a joint project with the Robot Systems and Automated Production Technology Divisions within MEL. The project is being supported by internal funding, Navy Mantech Program, and DARPA.

\section{Communications and Networking}

o MAP/TOP Laboratory - Its objective is to establish a lab environment which is representative of the computing environment and associated communication systems in state-of-the-art manufacturing facilities. Key to this project was a Cooperative Research and Development Agreement (CRDA) with General Motors signed in September 1992. A software tool, the 
Intelligent CIM Monitoring and Troubleshooting Tool (Intellimon), will be developed which can be used by an operator at a centralized location to track the data exchange between CIM applications, provide the operator with suggestions for maintaining a healthy networking environment and diagnose problems within the networking environment. This project is being supported by the Navy Mantech Program.

o Automated Processing System - Its objective is to develop the architecture and information technology standards for the U.S. Postal Service's mail distribution centers. Key accomplishments to this point include publishing a requirements document that specifies the communication protocols needed to integrate the automation equipment (e.g. letter sorters) in the centers. This project builds on the division's expertise in factory communication protocols such as manufacturing message specification (MMS) and the experience in developing the IMDAS prototype. This project is being supported by the U.S. Postal Service.

\section{Database and Database Management}

o Persistent Object Bases for Manufacturing - This project was initiated to perform technology evaluations of persistent object databases and their applicability in a distributed, STEP-based manufacturing environment. This project is being supported by DARPA.

\subsection{Long Term Program Objectives (FY94 - FY98)}

For the long term program objectives described in this section, there is a unique role that the Factory Automation Systems Division plays that makes these objectives different from other organization's. In carrying out its mission, the FASD has established a special relationship with standards organizations, R \& D institutions, other government agencies, industry end-users, and vendors (see Figure 2.) FASD works with its partners by providing testing methodologies, integration technologies, and feasibility demonstrations in support of the development of standards, technologies and world class products.

The ideal project will involve partners from all the defined aspects. Part of every project should be the creation of a special relationship through CRDAs involving industry, MOUs involving standards organizations, joint funding involving other government agencies, and grants involving research institutions. In both the AMRF and the NPT programs of the 1980's and early 1990s, these special relationships greatly contributed to the success of the programs and to the production of quality standards, new technologies and world class products.

\subsubsection{Approach/Technical Plan}

In order to meet the requirements of the industrial community for Advanced Manufacturing Systems and Networking a new paradigm has been developed to define the type of projects initiated by the Division. This paradigm consists of four major elements: (a) Active role in developing required standards, (b) Lead role in developing the testing and evaluation methods 
Standards

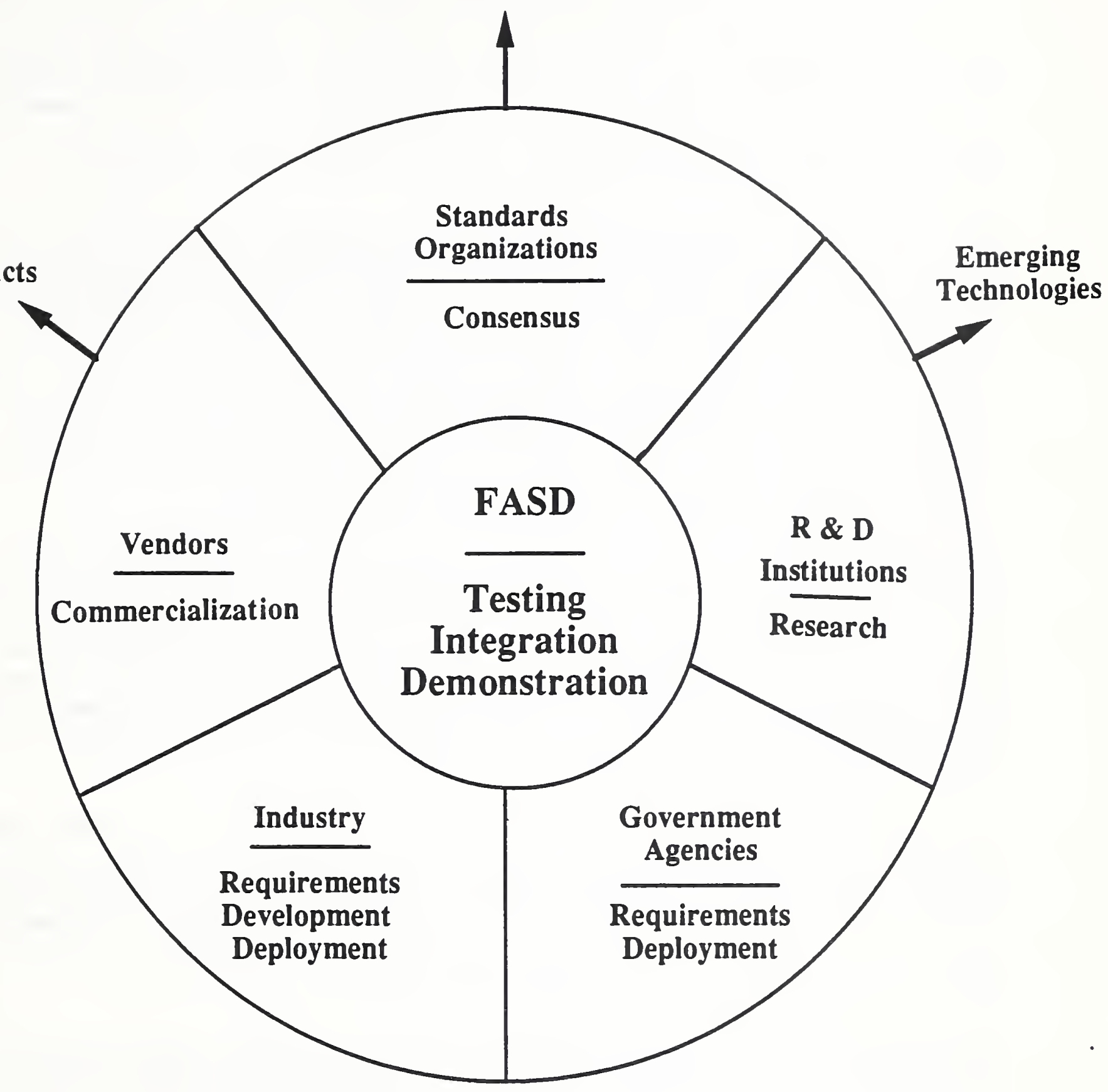

Working together to Produce World Class Products 
to ensure that quality standards are developed and implemented by vendors, (c) Research and development role into the technologies required to develop the standards and implement the advanced manufacturing systems that conform to the standards, and (d) Collaborative role with pilot facilities in implementing the FCIM standards through the involvement of FCIM vendors. This paradigm would be implemented through the AMSANT facility which will allow for a broad range of manufacturing data interface standards related to FCIM to be developed.

The first element, Standards Development, involves working closely with industry to identify the priorities for standardization and with the standards bodies to facilitate the development of such standards. Working under the auspices of ANSI, a U.S. industry driven standards policy in advanced manufacturing will be developed and used to drive international standards, with the cooperation of such major partners as the European Communities and Japan. As with the historical presence of NIST as the "holder of the meter," FASD will take on the role as the "holder of the advanced manufacturing standards" which will often be in electronic data form. In addition, FASD will be working with industrial consortia to get an industry driven effort in developing the standards. In fact, FASD now serves as the "holder of the standard" by providing configuration management services for the various STEP Parts.

The second element, Testing \& Evaluation Methods, involves developing a full range of testing methods that will insure that the standards being developed satisfy the industry needs and that the vendors produce systems that will conform to these standards. In addition, because of the multitude of competing proposals for developing a given standard, a performance testing methodology will be implemented that will allow for technical decisions to be made over the best way a standard should be specified. FASD can serve as the first line of accreditation for the standard implementations. In addition, FASD can then accredit other institutions to perform the conformance testing of vendor products.

The third element, Technology Development, involves implementing the tools needed for developing the standards and for prototyping the systems for which the standards are being specified. The research and development includes such areas as information technology (i.e., information modeling, database technology, specification languages), and advanced manufacturing systems (e.g. process planning, scheduling). Much of the efforts in "Integrated Tools for Product, Process and Enterprise Design" are performed under this element.

The fourth element, Pilot Site Implementation, will involve working with pilot production facilities as a basis for identifying and resolving advanced manufacturing system integration problems. Once these requirements are developed and expanded to include a broad spectrum of site requirements, FCIM vendors will implement the FCIM systems and interfaces for each of the pilot site applications. This effort will require the development of special software interfaces to the legacy systems and, if necessary, obtain the proprietary source code from the various Commercial Off The Shelf (COTS) software OEM's where the present applications do not satisfy the CIM interface standards. In addition, all COTS software upgrades must be received and tested and the software maintenance must continue during this Pilot Site 
Implementation period. The conformance testing application protocols that are being developed in the second element will be used to determine the correctness of the integration effort.

In order to make the program objectives realizable, FASD must be able to form close relationships with a wide variety of organizations:

o Standards bodies - Work to ensure that the collection of CIM standards are harmonized. This can be accomplished by active involvement in the ANSI CIM Standards Board. In addition, continue to perform such roles as chair of the national IPO, and accept other chair positions as appropriate. Continue to serve on all the appropriate standards committees. Provide the testing methodology and configuration control of the standards as appropriate. On the international level, continue to serve as chair of the ISO STEP committee and accept other positions as appropriate.

o U.S. Industry - Identify needs and facilitate the technology transfer of standards to industry. Form partnerships in the development of FCIM technology needed by industry.

o Government Agencies - Work with other government research laboratories (i.e. in DoE and $\mathrm{DoD}$ ) to implement FCIM technologies. Work with other government agencies to identify standards requirements that meet their specific needs.

o Universities - Define scope of technology problems that can be solved through university research activities.

o Pilot sites - Create a network of pilot sites to work together on the overall program objectives. This network will be called the FIN (FCIM Integration Network).

\subsubsection{Projects}

The following projects are typical examples of the type of research and development that would take place in the AMSANT Facility over the next five years:

\section{Enterprise Integration}

o Factory Engineering - Research into Computer-Aided Factory Engineering (CAFE) will be performed to develop technologies, methods, tools, and standards for Factory Engineering Systems. This research will promote the application of computer technology to the design and engineering of the nation's factories. Major outputs of this effort will include: (1) an architecture for computer-aided factory engineering systems that will permit the implementation of plug-compatible computerized tools, (2) development of a prototype factory engineering workstation, and (3) recommended standards for these systems. Components of the research include: (1) prototype factory engineering workstation, (2) factory engineering life cycle process definition, (3) factory engineering data models, (4) factory engineering system architectures and 
standards, and (5) factory engineering applications development.

o Integration Frameworks - New techniques for developing interface specifications will be developed. The initial work in manufacturing systems integration will be extended into the Enterprise Integration area. Frameworks for enterprise integrations will be evaluated for efficiency and completeness to cover a broad spectrum of enterprises. The enterprise case tools will be used to develop new interfaces and functional specifications for future standards. Research into the automatic generation of resource specifications from the basic enterprise functional specifications will be performed.

o Conformance Testing - Because of the importance of the data interface standards, research into conformance testing methods and upgrades to application protocol framework techniques will be used to extend the STEP efforts into other related data standards areas. Phases of conformance testing service include (1) select candidate APs and the supporting abstract test suite, (2) generate an executable test suite using the abstract test suite, (3) extend, if necessary and appropriate, the Validation Testing System at the National PDES Testbed, to provide the capabilities for application protocol conformance testing, (4) define the conformance assessment process carried out by a Testing Laboratory for a given client, and (5) provide a conformance testing service for implementors, government agencies and academia for the chosen application protocols.

o Modeling Engineering Data - Specifications of product information are tightly scoped and highly structured representations for the communication of multi-disciplined engineering information. Existing data modeling methods have not been adequate for representing engineering knowledge. It is expected that an universal engineering information representation will be developed that maximizes the reuse of existing models (e.g., from legacy systems.) A modeling methodology will be developed concurrently that directly supports creation and validation of models in the universal form. Specific problems to be addressed include: (1) management of temporal data with respect to varying states of processing in a product life-cycle, (2) schema change management, (3) viewing mechanisms for different application views, (4) security with respect to data communication, and (5) static and dynamic characteristics of product data as related to events.

o Process and Production Management Data Interchange - The goal of this project is to promote the development of open architectures, interfaces, and information models to support the management of manufacturing data. In addition to the product data, there is an additional set of issues associated with process and product data. This includes such functions as (1) order management, (2) workpiece tracking, (3) inventory data, (4) production models, (5) scheduling, (6) factory status, (7) job status, (8) process modeling, (9) factory resource modeling, and (10) factory configuration. All of these functions require information and approaches other than those supporting product data before they can benefit from interoperability obtained through an open architecture. Related communication standards (i.e. EDI, OSI, IRDS) must also be considered in implementing the standard. 


\section{Product Data Exchange}

o Level 4 STEP - The AMSANT will be available as a laboratory where the technology issues relating to a knowledgebase implementation of STEP can be studied. Key issues include (1) what knowledge is needed about each process and how to gather this knowledge through people and sensors, (2) how to manage the product data in such an environment, (3) how to represent product knowledge, and (4) efficient use of product knowledge through object oriented database methods.

o Application Protocol Development Environment (APDE) - The objective of this research will be to reduce the overall time and effort required to develop and standardize application protocols. Key issues include (1) developing AP needs analysis methodologies, (2) enhancing and implementing AP development methodology, (3) defining the architecture and specification for APDE, (4) building an APDE toolkit, and (5) implementing technology to effectively allow for AP interoperability through efficient use of Application Interpretive Constructs.

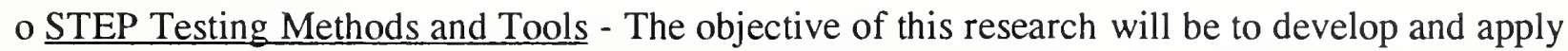
conformance testing methods and quality management procedures to implementations of STEP. Key issues include (1) development of a STEP quality management system, (2) development of STEP AP conformance testing tools, (3) testing tools for implementations such as STEP Data Access Interface, and (4) STEP interoperability testing guidelines.

o STEP Technology Development - The objective of this research is to define and provide proofs of concept for STEP implementation technology beyond file exchange and deliver tools for developing AP implementations. Key issues include (1) developing the STEP Data Access Interface Specification required for upper level STEP implementations, (2) developing implementation architectures, (3) developing STEP object oriented database toolkit, and (4) developing specific interfaces between STEP and external standards such as Open Systems Interconnect (OSI) and Electronic Data Interchange (EDI).

o Harmonization of STEP with Related Standards - STEP covers a broad section of existing application software for engineering. This project is intended to resolve the differences between four existing ANSI standards, IGES, VHDL, EDIF, and IPC-D-350. In addition to the existing electrical standards, STEP must also sort out how to mesh with standards for networking, databases, business information exchange, document exchange, and software languages. Top on the list of existing standards that should be considered are: OSI, EDI, SGML, ASN.1, IRDS, ISO-9000, and X3J16/WG21. There are several activities involved in harmonization: (1) Understanding the role of STEP and the assigned standard, (2) Identifying all cases where interfaces must be built between the standards, (3) Notification of all parties involved when a conflict occurs between the standards and following up until the conflicts are resolved, and (4) Insuring that STEP meshes with the existing body of standards in a logical and efficient manner.

o Application Protocol Development - The project is concerned with the implementation of application protocols that apply across a wide range of products such as mechanical, electronics 
\& electrical, apparel, distribution systems, and structures. The long term goal is to develop sets of application protocols that will be complete for a given type of product in a given application such as design or manufacturing. These applications allow for the testing of the proposed standards and to further understanding and improvements in the standards and methods. It is through the development of the applications and relevant application protocols that technology can be implemented and then transferred to industry.

\section{FCIM Processes}

o Concurrent Design - Given the concern over time-to-market, we must learn how to do concurrent design in a knowledgebase system environment. Once STEP can handle knowledge representation, issues that need to be addressed include: (1) how to make trade-off decisions between the different manufacturing processes as they relate to design, (2) how to efficiently represent design knowledge, and (3) how does a designer, or design team, really make decisions and can this be automated.

o Design Engineering - It has become evident that the U.S. must develop industry-wide capacity to product high quality and high style products that are responsive to consumer demands. Research into a new discipline, design engineering, will be conducted on how design technologies can be integrated. A part of this effort involves the extensions to STEP for the apparel industry. Efforts aimed at developing pattern description languages that can be incorporated into the design process will be pursued. In addition information over all the processes of the apparel life cycle will be integrated back into the design process.

o Tolerancing Theory and Technology - Research will be performed to develop sound mathematical basis for geometric tolerances and the relationship of geometric tolerances to surface roughness and texture and to process capability measures. Work will also take place to apply tolerancing theory to tolerance synthesis (design generation) and tolerance analysis (simulation).

o Fault-tolerant Systems - Architectures for reliable and fault-tolerant manufacturing systems will be developed. Current architectures are far from being sufficient to support an actual errorridden factory properly. Research will be conducted into techniques for real-time monitoring and diagnosis of system problems.

o Intelligent Systems - Once the AMSANT has been implemented, research will be directed towards developing "smart" systems for manufacturing engineering. Areas covered include intelligent scheduling, generative process planning, automated machining and automated inspection from a design specification. Research will be performed on learning control systems-systems that change embedded control models based on sensory input.

o Automated Equipment Program Generation - Research into the automatic generation of programs for manufacturing processes from design specifications will be performed. Methods for automatically developing the design specification itself from user requirements will be 
explored. Manufacturing processes are being studied and process capability data bases will be developed to support concurrent engineering applications, including design, process planning, and inspection planning. These systems will be used to test different theories of design semantics and tolerancing theories.

o Design Knowledge Representation - Design is the key to the development of a product. This project is concerned with developing, through the use of computer shared databases and knowledge, the ability to include information about all stages of a product's life cycle in the design process. This includes the development of the techniques to incorporate product knowledge (such as knowledge about the product's manufacture, maintenance and disposal) into the design system database, as well as the integration of appropriate computer representations of a product. Technical issues that need to be addressed include (a) computer representation of in-progress designs, especially feature-based representations, (b) common definition of design knowledge, (c) a model of decisions made during the design process to be used later in the product life-cycle, and (d) how STEP will provide for these representations.

\section{Communications and Networking}

o Open Distributed Processing and Open Shared Databases - The realization that concurrent engineering and enterprise integration require a logically centralized data repository leads to research on how to achieve this goal with networks, servers, and workstations. It is clear now that physical centralization on a single computer is neither practical nor desirable. Through the AMRF research of the last decade, FASD has a core of expertise in this area, and now is the time to study the integration of commercial and experimental systems in a demonstration manufacturing environment. Most information technology standards in place or under development would contribute directly to this project, and this project would be a testbed for those standards.

o Information Integration - Information is the life blood of most significant research activities. A number of new global networking and high-bandwidth user interface technologies are now available to address the issue of "high quality information integration." Research will be conducted into these technologies in order to achieve maximum performance of the most critical limiting factor in manufacturing research, the human factor. For example, the Division is working on a variety of information intensive standards, such as STEP. There needs to be a good, intuitive manner of viewing and manipulating the information required for defining the standard (e.g. application protocols for STEP.)

o Electronic Library Services - Mechanisms need to be developed that allow for quick exchange of information with the outside world. An on-line service needs to be developed that can transfer research information to industry, academia, and government organizations. This electronic form of technology transfer will enable researchers to gain timely access to information that would otherwise be out of date if transferred via other media. This service will also enable outside users to remotely access computational tasks that would otherwise be 
unavailable to them.

\section{Database and Database Management}

o Information Modeling - It has become clear that information modeling is essential to the development of data exchange standards. Research will be performed into what are the essential components of information modeling, how can different modeling methodologies work together, and how does an information modeling representation communicate with a data dictionary for implementing the actual database system. There is tremendous activity in the standards community to develop the set of information modeling standards required to address these research issues.

o Shared Database for STEP Applications - The STEP Level 3 Architecture requires a shared database system in which data in distributed repositories are made available to manufacturing applications through operations on the STEP-defined schemas. There are three types of problems to address: (1) Representation of the STEP schemas in a data dictionary that integrates non-STEP information with STEP data, (2) Definition of a means of describing the relationship between a STEP database schema and the data representation in the application in a given facility, and (3) Efficiency of using the object-oriented database paradigm as a shared database implementation. With a shared database implementation, each application is linked to a common database. However, STEP needs to be integrated with an enterprise's complete conceptual schema which likely includes non-standard private data. It is proposed to build a STEP Data Access Interface (SDAI) that allows the applications to communicate with the STEP Data Repository, integrating SDAI technology and Information Resource Dictionary System (IRDS) technology in order to support these manufacturing applications. In addition the STEP database implementations standards must be harmonized with the relevant OSI communication standards and the Electronic Data Interchange (EDI) standard [FINC92].

o National Repository for Design and Planning Knowledge - This project will promote the development of a national knowledge repository to support design and planning applications for product life cycle support. The focus is on the standards that allow for the access and manipulation of design and planning knowledge to support the product life cycle. Assuming that database technology will exist to support standardized knowledge based representations, advanced approaches can be made to address problems such as capturing design intent and cataloging process planning knowledge for use by automated planning systems. A national repository of product life cycle knowledge will provide a significant advantage in increasing U.S. industrial competitiveness. For example, a library of process plans with a standard classification of related process plans will enable a manufacturer to find and use a vast store of plans, rather than developing them each time.

\subsubsection{Road Map}

To meet the national objectives described in section 2.2, FASD will have to develop a plan that includes the active participation of a broad spectrum of organizations. The major contributions 
of the Division will be in the area of promoting the development and implementation of the technologies required for the manufacturing data interface standards. The development of the advanced manufacturing and communications technologies will be the primary responsibility of the industrial (and government laboratories within DoD and DoE) and academic research communities with a supporting role from FASD. The following is a strawman for a five year road map.

\section{Year 1:}

o Publish a plan that defines the road-map for implementing the AMSANT facility. Identify facility requirements, both hardware and software.

o Publish a set of prioritized requirements based on input from industry, standards organizations, and other government agencies that is responsive to the national objectives for advanced manufacturing systems and networking.

o Publish a plan that defines the road-map for implementing the prioritized requirements through a series of technical projects and associated deliverables.

o Publish a plan for the new organizational structure for the Division needed to meet the roadmap objectives.

o Identify and participate in relevant standards organizations.

o Initiate the Affiliates' program.

o Provide the means for nationwide collaboration through an electronic bulletin board, work shops, and laboratory access to leverage developments concerning the AMSET.

o Establish a clearing house for formal models of the manufacturing processes in STEP form for access by industry and universities.

o Publish a plan that identifies the overall standards requirements for advanced manufacturing. The plan will include a description of all the critical standards, how they relate, and a road-map for development.

\section{Year 2:}

o Set up design workstation with existing tools. Incorporate computer representation of inprogress designs, especially feature-based representations. Determine requirements for design process management tools that can support distributed design and manufacturing. Develop a software platform that uses a small set of pattern "primitives" that can be used to study the apparel design process, new sizing technologies for apparel, aesthetic considerations, etc.

o Obtain consensus on common reference framework for enterprise. Publish specifications of the enterprise model methodology needed for multi-enterprise concurrent engineering. Model selected assemblies and manufacturing processes.

o Acquire and install factory engineering/system integration tools.

o Publish specification on format for process knowledge.

o Demonstrate application protocols required for some processes (i.e. process planning and 
design). Publish verification and validation testing methods for STEP specification. o Make available more advanced information modeling languages and tools to support the data information standards development.

o Initiate intensive activities in the identified standards to accelerate the development of the standards. Publish description of the testing methodology required.

\section{Year 3:}

o Extend capability of design workstation to incorporate analysis and simulation tools, with availability of quality-cost models for use on applications. Develop a formal representation of the design process, generalized from the design process modeled in the specific domains of apparel, mechanical, and electrical products. As a consequence of the apparel software platform, identify and develop prototype design tools for the apparel industry that can be commercialized.

o Extend enterprise model methodology into several industrial applications. Develop framework for standards needed for enterprise integration.

o Develop distributed database framework to support enterprise. Incorporate data security into database framework.

o Publish an architecture for computer-aided factory engineering systems.

o Demonstrate process knowledge capturing and product knowledge representation in specific applications. Publish architecture for product data driven processing as draft standard.

o Demonstrate use of application protocols for various electronic, apparel, structures and distribution applications. Publish architecture for supporting product data sharing capability as draft standard. Demonstrate a shared product database that can support these application protocols.

o Make available more advanced database technology to support FCIM data requirements (e.g. extensions to data dictionaries and object oriented methods).

o Develop a curriculum for AMSANT disciplines.

o Extend the testing methodology from the validating testing area to the conformance testing area under the assumption that the standards will have reached the point where vendors are ready to produce the systems.

\section{Year 4:}

o Develop definition of design knowledge. Demonstrate encoding and dissemination of design knowledge. Incorporate the theory of tolerances into design knowledge. Demonstrate intelligent design workstation that incorporates design knowledge. Develop both short and long term tools for managing the design process. Short term tools should include some form of engineer's notebook in electronic form. Integrate information from other processes in the apparel manufacturing life cycle into the design process using STEP technology, enterprise frameworks, etc.

o Develop toolset for implementing enterprise models. Develop information modeling techniques for enterprise specifications. Develop conformance testing methodology for framework standards. 
o Develop and demonstrate a prototype factory engineering workstation.

o Extend FCIM processes to be product data driven. Publish metrics for process performance. o Implement all application protocols needed in design area for STEP and submit draft standard. Publish conformance testing procedures for STEP. Develop extensions to STEP to support product knowledge.

o Publish architectures for supporting product and process knowledgebase capability as draft standard.

o Develop the educational material, including software, for teaching and training in AMSANT disciplines.

o Initiate conformance and integration testing activities at contractor and manufacturing sites. Analyze results, amend specifications, and modify software, as required. Make available prototype systems at the AMSANT to demonstrate how the standards will be used in actual industrial applications. Conduct performance evaluations of the standards and provide feedback to the standards organizations for future versions of the standards.

\section{Year 5:}

o Demonstrate intelligent design workstation that incorporates the tools and knowledge needed for designing a complex product. Develop architecture for design tools functionality. Submit interface standard for design tool integration. Publish formal methodology for design work station. Develop the theory and methodology for merging the creative and engineering processes for apparel design.

o Submit draft standard for common reference framework and enterprise model methodology. Publish framework for standards for enterprise application integration.

o Demonstrate multi-enterprise concurrent engineering environment that can be used for manufacturing a product such as an engine.

o Recommended standards for factory engineering systems.

o Finalize harmonization with existing standards in information technology. Make recommendations on data interface standards implementations based on demonstrated performance.

o Finalize harmonization among product and application types for areas of specification languages, modeling methodologies, implementation architectures, and conformance testing procedures.

o Submit draft standard for the application protocols required for manufacturing product.

o Conclude conformance and integration testing activities at pilot sites. Refine specifications and submit to appropriate standards bodies. "Systematize" the entire spectrum of standards, the testing and evaluation methods, and the supporting technologies in a definitive report on CIM Interface Standards Evaluation \& Technology.

\section{Funding}

For the past several years the Division budget has remained at approximately the $\$ 7.5 \mathrm{M}$ level. There are primarily two types of funding available to the Division: (1) NIST-supported such as 
base program, Director's Reserve, Competence, new initiative, and ATP collaborative participation; and (2) Other Agency supported.

In the case of NIST-supported, it is only the base program and new initiative funding that allow for the opportunity to perform long-term research and development. The other types of funding are short-term existing from one to four years in duration.

The other agency support comes with a one year commitment only. Despite this constraint, there are many projects within the Division that have been funded for several years with new statement of works generated annually (e.g. CALS/STEP project has existed since 1988.) It is very difficult to perform long-term planning under this environment because of the possible cancellation of projects, which can occur at any time and for reasons not related to the merit of the projects' deliverables. In addition, the Division seldom has the flexibility to consider broadbased industry problems, but instead limits its approach to solving the funding agency's problem.

\subsection{Current Overall Funding Profile}

As is typical of every year, the Division's budget is never fixed at any time during the fiscal year. Some projects are funded from the start of the year, but many are not initiated until well into the year. In addition, at any time during the year, new projects can be created based on agreements with new sponsors.

At the current time, the Division's budget is approximately $\$ 8 \mathrm{M}$, with about $\$ 270 \mathrm{~K}$ of other agency year-end carry over and $\$ 400 \mathrm{~K}$ of ATP carry over.

For NIST-type funding, the Division has $\$ 1.6 \mathrm{M}$ of base program funding (specified for AMRFrelated projects and chairing the IPO/ISO product data standards organizations), $\$ 500 \mathrm{~K}$ of ATP funding (for the next 3 years to support the RRM requirements), $\$ 130 \mathrm{~K}$ of funding from another laboratory (MSEL in Metal Powder Processing), and approximately $\$ 300 \mathrm{~K}$ for Director's Reserve (one-year funding in MAP/TOP and STEP projects).

For other agency funding, the Division has approximately $\$ 5 \mathrm{M}$ including carry over with approximately half in the area of Product Data Sharing Technology and Standards.

\subsection{Review of Funding Sources}

Most of the Division's funding is derived from technical and standards-related projects that are supported by other government agencies. Several of the projects are also supported to some degree with NIST funding where there is the possibility of leveraging the two funding sources in areas of common interest. Government agencies are listed below with the projects being supported (note that some are only carry over):
Air/Force Mantech
Enterprise Integration Framework
DARPA
Manufacturing Research Testbed 


$\begin{array}{ll}\text { Defense Log. Agency } & \text { PDES for Apparel } \\ \text { DoD/CALS } & \text { National PDES Testbed } \\ \text { Navy/Mantech } & \text { Factory Engineering } \\ & \text { Interorganizational use of STEP } \\ & \text { (collaboration with ITI) } \\ & \text { Conformance Testing for STEP } \\ & \text { (collaboration with ITI) } \\ & \text { Best Manufacturing Practices } \\ & \text { MAP/TOP Lab (collaboration with GM) } \\ & \text { Reverse Engineering (North Island) } \\ & \text { Reference Architecture for Control } \\ & \text { (collaboration with Robot Systems Division) } \\ & \text { Intelligent Modules for CIM } \\ & \text { (collaboration with IMAR) } \\ & \text { Software Performance for CMM } \\ & \text { Learning and Process Control } \\ & \text { (collaboration with MSEL) } \\ & \text { Postal Equip. Message Specification }\end{array}$

Persistent Object Base Evaluation

National Process Planning Testbed

Machine Tool Controller

(collaboration with MEL Divisions)

PDES for Apparel

National PDES Testbed

Factory Engineering

Interorganizational use of STEP

(collaboration with ITI)

Conformance Testing for STEP

Best Manufacturing Practices

MAP/TOP Lab (collaboration with GM)

Reverse Engineering (North Island)

Reference Architecture for Contro

(collaboration with Robot Systems Division)

Intelligent Modules for CIM

IMAR

Software Performance for CMM

Learning and Process Control

\subsection{Plan to Increase Resources (e.g. Business Development Plan)}

In order for the Division to increase resources, it is necessary to establish a broad-based technical program that will be supported by NIST (DoC) funding. With an increase in base support, it would be possible to perform more efficient long-term planning, and through this mechanism maintain, if not increase, other agency funding as well. Over the past three years, the Division has been encouraged by NIST to submit new initiatives in Product Data Sharing (e.g. PDES/STEP). The first initiative was approved in FY91 by Congress at the $\$ 750 \mathrm{~K}$ level and presently supports the chair activities for both IPO and ISO. The FY92 initiative at $\$ 1.5 \mathrm{M}$ and the FY93 initiative at $\$ 2.8 \mathrm{M}$ were not approved by Congress.

The following steps will be taken to implement a plan to increase the resources for the Division:

o Develop a supportive "customer base" in industry that will actively promote the acceptance of FASD activities as key to solving their requirements.

This step will be accomplished through holding workshops where "customers" are invited to develop the consensus view on the role of FASD. In addition, FASD staff will continue to work actively with industry through various project collaborations, workshops, panels, and committees.

o Based on documented customer requirements, develop new program initiatives to submit to 
Congress.

Use as the basis of the initiatives the framework provided by the FCCSET Advanced Manufacturing Initiative thrust - Integrated Tools for Product, Process and Enterprise Design and the High Performance Computing and Communications thrust - Technologies for Systems Integration. This includes developing a vision of 21 st century manufacturing that includes the facilities and yearly deliverables to implement the vision.

o Implement a new facility known as the "Advanced Manufacturing Systems and Networking Testbed" (AMSANT).

AMSANT will provide the opportunity to demonstrate the technology and standards supported by the Division. It will allow for the projects presently in the Division to have a common denominator.

o Develop an integrated plan for the Division's activities.

It is imperative to develop a synergism between the many "other agency" projects and the programs created from the DoC initiatives that will result in a leveraging of deliverables between projects.

o Work with industry to encourage more ATP proposals in areas that involve FASD research and development.

The ATP provides a convenient mechanism for obtaining one to four year funding that allows for collaboration with industry.

o Maintain the Division's visibility in external activities.

This can be accomplished by increasing the number of "quality publications, " continuing to serve on committees and panels, and active participation in standards organizations.

o Increase level of collaboration with industry as means of improving technology transfer.

Develop new Cooperative Research and Development Agreements that brings additional resources from industry to NIST to work on problems of common interest.

o Increase level of collaboration with other divisions at NIST, both within MEL and throughout NIST.

Find areas of common interest with other divisions and propose joint projects that require skills and expertise from both FASD and outside staff.

o Increase level of collaboration with other government research laboratories.

Find partners in the DoD and DoE to promote joint projects in FCIM.

\subsection{Budget Expectations}

To operate a program that addresses the national objectives for implementing FCIM and SMT technologies will require a budget of $\$ 12 \mathrm{M}$ for the Division. If the Division can maintain its Other Agency funding at $\$ 5 \mathrm{M}$, then the present level of NIST funding must be increased from 
$\$ 1.6 \mathrm{M}$ of base funding to $\$ 7 \mathrm{M}$. This can be accomplished by getting Congressional approval for a $\$ 5.4 \mathrm{M}$ initiative in "Integrated Tools for Product, Process, and Enterprise Design" and "Technologies for Systems Integration."

\section{Organization}

The Division is located within the Manufacturing Engineering Laboratory (MEL), which is one of the eight technical laboratories at NIST. In addition to FASD, there are four other Divisions in MEL: Automated Production Technology, Fabrication Technology, Precision Engineering, and Robot Systems. There are two offices: Manufacturing Programs and Industrial Relations.

Divisions at NIST are organized into technical groups and program offices. In the case of any of the technical groups in FASD, the work includes not only advancing the state of the art in relevant technologies, but active participation in national and international standards bodies to ensure that such technologies can be implemented by U.S. industry under the overall framework of Flexible Computer Integrated Manufacturing. As part of each group's mission, it is expected that efforts will be undertaken to provide the following functions: technology transfer of group's efforts to industry, conformance testing methods for vendor implementations of technology, training for industry on effective use of technology, and mechanisms for the exchange of information about the technologies.

\subsection{Current Organization}

The Division has a total staff of 55 that fall into the following categories: Technical Professionals -42 , Support - 8, Administrative - 2, and Technicians - 3. There are presently 5 supervisors - Division chief, deputy division chief, and three group leaders. There are nine top level professionals (i.e. ZP5 pay band level).

At the current time, there are three groups in the Division: Production Management Systems, Product Data Engineering, and Machine Intelligence. There is one program office: IGES/PDES/STEP Administrative Office.

The Production Management Systems Group performs research and development work to advance the state of the art for manufacturing systems and to identify open interfaces that will support interoperability, when these systems are used by different vendors. Examples of the types of systems addressed include control architectures, cell controllers, production scheduling, process planning, and off-line programming.

The Product Data Engineering Group performs research and development into the technologies required to develop a standard product data model. Such technologies include product data modeling, data access and storage, software tools, and testing procedures.

The Machine Intelligence Group performs research and development in such areas as metal powder production, apparel product data exchange, inspection software performance testing, and 
inspection methods with an increasingly focused effort in mechanical tolerancing and related issues.

\subsection{Human Resource Needs for the Future}

If the Division is to be committed to taking a leadership role in the implementation of the technologies and standards required to support the FCIM and SMT national objectives (see section 2.2), a strategy for developing the resources is needed. The following steps will be necessary, assuming that the funding will be available over the five year time frame:

o Reorganize the groups within the Division to correspond to the major technical areas within FCIM and SMT.

There were five areas described: Enterprise Integration, Product Data Exchange, FCIM

Processes, Communications and Networking, and Database and Database Management. o Provide effective leadership in Division's programs.

For each of the groups that are created, there must be a qualified leader who has the technical and management skills to meet the national objectives.

o For each of the objectives for the Advanced Manufacturing Systems and Networking Testbed, which will serve as the integrating mechanism for all the Division's facilities and projects, develop the skills for implementing these objectives.

The objectives require skills in (1) manufacturing systems and networking research and development, (2) integration tools, (3) standards participation, (4) testing methods, (5) multimedia and interactive learning technologies for training and technology transfer, and (6) information exchange technology.

o Reorganize the office(s) within the Division to be responsive to the needs of national and international standards issues.

The most important contributions that the Division can make to industry is to facilitate the development and implementation of data interface standards for manufacturing. Skills in standards consensus and the overall standards development process are critical.

o Provide effective facility management.

The new AMSANT facility, along with the National PDES Testbed and the other existing and future testbeds, need strong leadership. Managers are needed who have good matrix management skills, and can effectively coordinate the meeting of the required deliverables.

In order to meet the resource objectives, the following goals need to be achieved:

o The size of the Division needs to be increased to 80 staff in order to properly staff the expected number of groups and offices.

o The number of PhDs needs to be increased to 20 to reach the NIST ratio level of PhDs to technical staff (i.e. 33\%).

o The number of supervisors needs to be increased to handle the expected number of groups and offices.

o Facility managers need to be recruited as the facilities are put in place. 
In order to meet the challenges of the research agenda defined in this chapter, the factory automation systems engineers of the future will have to be trained in the following new skills:

Information Modeling - the ability to abstract from available data to the conceptual level and express this in a conceptual modelling language.

Software Engineering Life Cycle - both an appreciation for the value of the life cycle phases (requirements, design, implementation, testing, maintenance, ...), and experience in using the different technologies available in support of software engineering (e.g. OOA, OOD, testing approaches) needs to be developed.

Computer Literacy - a working knowledge of user basics of operating systems, user interfaces, databases, networks, etc.

CASE Tools - both an understanding of what CASE (Computer Assisted Software Engineering) is, the benefits of it, and knowledge of how to use relevant CASE tools are required.

Specialty Software - knowledge of the capabilities of software specifically for manufacturing such as CAD/CAM systems, schedulers etc. and an introduction to the integration issues in factory automation.

Teamwork - experience and knowledge in teamwork (e.g., consensus building) is critical to developing technology and standards in a timely fashion and in the efficient operation of manufacturing facilities.

\section{Facilities}

\subsection{Current}

At the current time, the Division makes use of a variety of facilities in carrying out its research. The following is a list of the facilities grouped under the National Objectives categories (see section 2.2):

\section{Enterprise Integration}

o The Computer-Aided Factory Engineering (CAFE) laboratory is just being initiated and will contain a collection of workstations with a variety of case tools and software systems that are being integrated into a CAFE environment. The laboratory will promote the application of information technology to the design and engineering of factories.

\section{Product Data Exchange}


o The National PDES Testbed (NPT) testing facility, in place for several years for validation testing of STEP part models, will be available for performing conformance testing and interoperability testing on APs as they are defined. In addition, early validation testing capability will be available through a broad range of toolkits obtained from industry.

\section{FCIM Processes}

o The Rapid Response Manufacturing Facility (RRMF) is being established as part of the Division's interaction with the ATP Rapid Response Manufacturing program (i.e. NCMS consortium). This will be a STEP-based manufacturing machined parts facility. This facility will make use of knowledge-based systems to allow for intelligent integration of the manufacturing process. Critical research into knowledge representation schemas will be required in order to develop the set of knowledge-based rules for each of the major manufacturing processes. There will be an integrated network of design workstations, machine tools, in-process and post-process inspection systems, and process planning/NC/Inspection programming systems all sharing information from a common knowledgebase system.

o The Process Planning Testbed was established to encourage open collaborations between process planning researchers from government, academia and industry. The testbed will service information management and communication needs of the process planning community by providing on-line access to relevant information bases, mailing lists, and by conducting regular workshops. It will also provide a suite of system development and integration tools, along with databases containing sample populations of process plans, factory models, and designed parts to facilitate integrated process planning system development. The testbed will serve as a conduit of information on issues and advancements in the field of process planning, and help unify development approaches adopted by academia, industry and government research programs.

o The Design Laboratory provides a wide range of design analysis tools and "design for

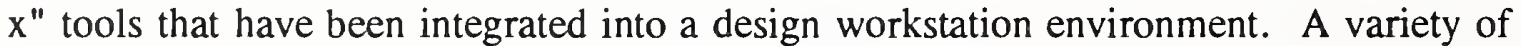
CAD systems are available for use. These systems will be integrated over the FASD network into the AMSANT. The design systems will all have interfaces to STEP application protocols. A library of design knowledge for various applications will be available for use.

o The Algorithm Testing System (ATS) Laboratory provides the ATS as a mechanism to test the performance of curve- and surface-fitting software used on coordinate measurement machines.

\subsection{Planned}

As was stated earlier (see section 4.1) the Division will make use of a new facility known as the 
"Advanced Manufacturing Systems and Networking Testbed" (AMSANT). Division projects will revolve around this facility. This will require the implementation of specific testbeds that address issues identified in the FCCSET "Integrated Tools for Product, Process and Enterprise Design". These issues range over five special areas: Enterprise Integration, Product Data Exchange, FCIM Processes, Communications and Networking, and Database and Database Management.

The following steps should be taken to develop a strategic plan for implementing the facilities:

o Develop an architecture for the AMSANT Facility.

This architecture includes the equipment, systems, interface requirements and functionality.

o Based on the overall facility requirements, define a set of testbeds with different functionality.

o Prioritize the order in which the facilities need to be developed.

This prioritization is based on the road map developed in section 5.4.3.

o Construct facilities as projects are initialized.

\section{Summary}

By the year 1997, U.S. industry will finally realize the capability of getting quality products to the market place in a time critical manner. The Concurrent Engineering methodology will finally take hold. Companies will take giant steps to breaking down the barriers between departments within the companies. Cultural changes will occur that will encourage staff to work together as teams in designing and implementing the processes required to manufacture "world class" products.

Concurrent engineering will require the ability to store and retrieve product data far beyond the capability of the mechanical drawing. The replacement for the mechanical drawing that will allow the new engineering technologies to be implemented in a revolutionary manner is Product Data Sharing. This new capability will make available to the designer knowledge about all other processes. It will process product data through automated computer-based techniques that allow for shared access among the life-cycle processes in support of concurrent engineering. It will make available an integrated product data model that allows for the multiple views of the product to be accessed. New data interface standards and supporting technologies must be developed for this new product data sharing capability to be successful.

Industry is demanding of the research community that technologies and systems be available that can be utilized in the product life cycle under the banner of concurrent engineering. In addition, the complex relationship between U.S. companies, both large and small, and the increased interaction with European and Japanese companies have made it clear that Manufacturing Data Interface Standards are needed to allow for all companies with their own cultural and vendor specific systems to work together. There is a national commitment to the development of tools and methods for how to implement technical standards that are accurate and useful and timely. The FCCSET thrust in "Integrated Tools for Product, Process and Enterprise Design" along with 
the data interface standards will allow for the effective integration of the product and process development required to implement the enterprise framework for producing world class products. The concept of developing technical standards before the commercialization of the associated products will take hold of the U.S. industrial community. Technology advances are occurring so rapidly that the previous standards activities can not keep up with the demand for technical standards. The world community realizes the importance of objective technical standards such as those embodied in manufacturing data interface standards and is putting more pressure on the international standards efforts to approve standards quickly so that international concurrent engineering process needs can be met.

\section{Acknowledgement}

This report consists of contributions from most of the staff in the Division.

\section{References}

[ALGE92] Algeo, M.B., Hopp, T.H., "Form Error Models of the NIST Algorithm Testing System," NISTIR 4740, January 1992.

[AM92] Agile Manufacturing Forum, "21st Century Manufacturing Enterprise Strategy An Industry-Led View," Published by the Iacocca Institute, Bethlehem Penn., November 1991.

[AMI92] Advance Manufacturing Initiative Industrial Working Group, "Crafting a Common Manufacturing R\&D Agenda," Letter to the Honorable Robert M. White, Under Secretary for Technology, U.S. Department of Commerce, August $5,1992$.

[AMIC89] ESPRIT Consortium AMICE eds., 1989, Open systems architecture for CIM, (Springer-Verlag, Berlin, Germany).

[ATP92] "Advanced Technology Program - Proposal Preparation Kit for Proposal Solicitations - ATP 92-01 and 93-01", (Available through the ATP Program located at NIST, Gaithersburg, MD.)

[BLO083] Bloom, H.M., McLean, C.R., "Standardization Suggested by the AMRF--A Research Testbed of the Factory of the Future," Proceedings of the ASTM Symposium on Automated Manufacturing; reprinted in Automated Manufacturing, ASTM STP 862, April 1983.

[BLO084] Bloom, H.M., and Furlani C.M., "Emulation as a Design Tool in Real-Time Control Systems," Proceedings of the IASTED Conference on Simulation and Modeling, San Francisco, CA, June 1984. 
[BLO088] Bloom, Howard, Furlani, Cita, Mitchell, Mary, Tyler, Joan, and Jefferson, David, 1988, Information resource dictionary system: an integration mechanism for product data exchange specification, NISTIR 88-3862, (National Institute of Standards and Technology, Gaithersburg, Maryland).

[BLO089] Bloom, H.M., "The Role of the National Institute of Standards and Technology as it Relates to Product Data Driven Engineering," NISTIR 89-4078, April 1989.

[BL0092] Bloom, H.M., Masters, L.W., "The Technical Program of the Factory Automation Systems Division 1992," NISTIR 4856, May 1992.

[BREE91] Breese, J.N., McLay, M., and Silvernale, G., "Validation Testing Laboratory User's Guide," NISTIR 4683, September 1991.

[BROW87] Brown, P. F., and Ray, S.R., "Research Issues in Process Planning at the National Bureau of Standards," Proceedings of the 19th CIRP International Seminar on Manufacturing Systems, Pennsylvania State University, June 1987.

[CARV91] Carver, G.P., Bloom, H.M., "Concurrent Engineering Through Product Data Standards," NISTIR 4573, May 1991.

[CATR91] Catron, B.A., and Ray, S.E., "ALPS: A Language for Process Specification," published in the Journal of Computer Integrated Manufacturing, Vol. 4, No. 2, pp. 105-113, 1991

[CLAR90] Clark, S.N., "QDES Administrative Guide," NISTIR 4334, May 1990.

[CLAR92-1] Clark,S.N., "The NIST PDES Toolkit: Technical Fundamentals," NISTIR 4815, April 1992.

[CLAR92-2] Clark, S.N., "Transformr: A Prototype STEP Exchange File Migration Tool," NISTIR 4944, October 1992.

[CLARK92-3] Clark, S.N, Libes, D., "FED-X: The NIST Express Translator," NISTIR 4822, April 1992.

[CLAR92-4] Clark, S.N., Libes, D., "NIST Express Working Form Programmer's Reference," NISTIR 4814, April 1992.

[DACA90] D. Appleton Company, Inc., " Comparison of Enterprise Integration Framework Characteristics Versus Those of Other Known Integration Programs," 1C-EJG843-030-001, March 26, 1990. (presented to DoD sponsor for the EIF project) 
[DCTP91] The Department of Defense, "Critical Technologies Plan for the Committees on Armed Services, United States Congress," Report AD-A234 900, 1 May 1991.

[ESPR91] "Report of the Workshop on Esprit/NIST Collaborative Action for Manufacturing Technologies," Berlin, July 29 -August 2, 1991.

[ETSI90] Directory of European Standardization Requirements for Advanced Manufacturing Technology, 1990, prepared by Information Technology Advisory Expert Group on Advanced Manufacturing Technologies, Memorandum M-IT-04, (CEN/CENELEC and ETSI, Brussels, Belgium).

[FEEN91] Feeney, A.B., "Engineering Design Laboratory Guide," NISTIR 4519, February 1991.

[FENG91] Feng, S.C., and Hopp, T.H., "A Review of Current Geometric Tolerancing Theories and CMM Inspection Data Analysis Algorithm," NISTIR 4509, February 1991.

[FENG92] Feng, "Comparison of ISO 10303 Part 47 Draft with ANSI and ISO Tolerancing Standards for Harmonization and Completion of Part 47," NISTIR 4744, January 1992.

[FINC92] Fincher, Judith A., "EDI -- Electronic Data Interchange : What is EDI and How is it Used?," published in CALS Journal, Volume 1, Number 1, Page 88, Spring 1992.

[FOWL90] Fowler, J.E., "STEP Production Cell Technical Development Plan," NISTIR 4421, September 1990.

[FOSS90] Fossum, Barbara, and Ettlie, John, 1990, The reconciliation of MIS and manufacturing for integrated manufacturing, Proceedings of CIMCON 90, Jones, A. Ed., (National Institute of Standards and Technology, Gaithersburg, Maryland).

[FREC90] Frechette, S., and Jurrens, K., "Development Plan: Product Data Exchange Network," NISTIR 4431, September 1990.

[HICK92] Hicks, William L., "Joint CALS : Business Opportunity or Threat?," Published in CALS Journal, Volume 1, Number 2, Page 37, Summer 1992.

[HOPP84] Hopp, T.H., "CAD-Directed Inspection," 14th CIRP General Assembly, Madison, Wisconsin, August 1984, reprinted in Annals of the CIRP, Vol. 33/1, pp. 357-361. 
[HOPP87] Hopp, T.H., "AMRF Database Report Format: Part Model," NBSIR 87-3672, September 1987.

[IDEF81] IDEF1 Information Modeling Manual, 1981, ICAM Program Office, WPAFB, Ohio 45433.

[ISO90] ISO TC 184/SC 5, 1990, Report form CEN/CENELEC on the progress of their work on CIM architecture, N187, (National Electronics Manufacturers Association, Washington DC).

[JACK92] Jackson, R.H.F., Leondes, C.T., editors, Three Pillars of Manufacturing, Control and Dynamic Systems, Vol. 45: Manufacturing and Automation Systems: Techniques and Technologies, Academic Press, Inc., 1992 .

[JONE86] Jones, A.W.T., and McLean, C.R., "A Proposed Hierarchical Control Model for Automated Manufacturing Systems," Journal of Manufacturing Systems, Vol. 5, No. 1, p. 15, 1986.

[JONE89] Jones, Albert, Barkmeyer, Edward, and Davis, Wayne, 1989, Issues in the design and implementation of a system architecture for computer integrated manufacturing, International Journal of Computer Integrated Manufacturing, 2, 65-76.

[KATZ91-1] Katz, S., "STEP On-Line Information Service User's Guide," NISTIR 4491, January 1991.

[KATz91-2] Katz, S., "Configuration Management Concepts Document," NISTIR 4538, March 1991.

[KATZ91-3] Katz, S., "Configuration Management of the STEP Documents: Procedures and System Requirements," NISTIR 4629, July 1991.

[KRAM88] Kramer, T.R., "Process Planning for a Milling Machine From a Feature-Based Design," Proceedings of AMSE Manufacturing International '88, Atlanta, GA, April 1988, Vol. III.

[LEE90] Lee, Y.T., "On Extending the Standard for the Exchange of Product Data to Represent Two-Dimensional Apparel Pattern Pieces," NISTIR 4358, June 1990.

[LEE92] Lee, Y.T., "Apparel Product Data Exchange standard," published in the Proceedings of the Third Annual Academic Apparel Research Conference, Atlanta, GA, February 17, 1992. 
[LIBE88] Libes, D., and Barkmeyer, E.J., "The Integrated Manufacturing Data Administration System (IMDAS) - An Overview," International Journal of Computer Integrated Manufacturing, Vol. 1, No. 1, p. 44, 1988.

[MCC91] "Technical Issues of Enterprise Integration", MCC Report CAD-349-91, 1991.

[MCLE86] MCLean, C.R., and Wenger, C.E., "The AMRF Material Handling System Architecture," Proceedings of the Fifth Annual Control Engineering Conference, Roset, IL., May 1986.

[MCLE90] McLean, C.R., "National PDES Testbed Strategic Plan," NISTIR 4438, October 1990.

[MITC90] Mitchell, M.J. "Validation \& Testing Systems Technical Development Plan," NISTIR 4417, January 1990.

[MITC91] Mitchell, M.J., "A Proposed Testing Methodology for STEP Application Protocol Validation," NISTIR 4684, September 1991 .

[MONC88] Moncarz, H.T., "Architecture \& Principles of the Inspection Workstation," NBSIR 88-3802, June 1988 .

[MONC91] Moncarz, H.T. and Lee, Y.T., "Apparel STEP Translator," NISTIR 4612, June 1991.

[MORR90] Morris, K.C., "Translating Express to SQL: A User's Guide," NISTIR 4341, MaY 1990.

[MORR91] Morris, K.C., Mitchell, M.J., and Sauder, D.A., "Validating STEP Application Models at the National PDES Testbed," NISTIR 4735, December 1991.

[MORR92] Morris, K.C., Sauder, D.A., Ressler, S., "Validation Testing System Reusable Software Component Design," NISTIR 4937, October 1992.

[MTC92] Suenram, Richard, "The Manufacturing Technology Centers Program: A Sampling of Individual Case Histories," NIST Special Publication 830, February 1992.

[NAU87] Nau, D.S., and Luce, M., "Knowledge Representation and Reasoning Techniques for Process Planning: Extending SIPS to do Tool selection," Proceedings of the 19th CIRP International Seminar on Manufacturing Systems, 1987.

[NCTP91] "Report of the National Critical Technologies Panel," National Critical Technologies Panel, W.D. Philips, office of Science and Technology Policy, Chair (1991). 
(Available from The National Critical Technologies Panel, 1101 Wilson Boulevard, Suite 1500, Arlington, VA 22209.)

[NICK90] Nickerson, D.A., "The NIST SQL Database Loader: STEP Working Form to SQL," NISTIR 4337, MaY 1990.

[NIPD91] "National Initiative for Product Data Exchange (Implementation Plan)," November 13, 1991 (available from the NIPDE office at NIST, Gaithersburg, MD).

[NRC91] "Improving Engineering Design: Designing for Competitive Advantage," published by the National Research Council, National Academy Press, 1991.

[OSEL89] Osella, S.A., "Collective Learning Systems: A Model for Automatic Control," Proceedings of the 4th International symposia for Intelligent Control, October 1989.

[OSEL91] Osella, S.A., Ridder, S.D., Biancaniello, F.S., Espina, P.I., "The Intelligent control of an Inert-Gas Atomization Process," published in the Journal of the Minerals Metals \& Materials Society (JOM), January 1991, Vol. 43, No. 1, pp. 18-21.

[OTA92] U.S. Congress, Office of Technology Assessment, Global Standards: Building Blocks for the Future, TCT-512 (Washington, DC: U.S. Government Printing Office, March 1992.).

[PALM91-1] Palmer, M., "Planning Framework for STEP Deliverables," to be published.

[PALM91-2] Palmer, M., "Guidelines for STEP AP Development and Approval," to be published.

[RAY87] Ray, S.R., "Process Reasoning," Proceedings of the IFIP WG5.7 Working Conference on Information Flow in Automated Manufacturing systems, Gaithersburg, MD, August 1987.

[RAY92-1] Ray, S.R., Wallace, S., "A Production Management Information Model for Discrete Manufacturing," for publication in production Planning and Control, 1992.

[RAY92-2] RaY, S.R., "Using the ALPS Process Plan Model," published in the Proceedings of the Manufacturing International Conference, March 29-April 1, 1992, Dallas, TX.

[RESS90] Ressler, S., and Katz, S. "Development Plan: Configuration Management systems and Services," NISTIR 4413, September 1990. 
[RESS91] Ressler, S., "The National PDES Testbed Mail Server User's Guide," NISTIR 4508, January 1991.

[RYBC88] Rybczynski, S., Barkmeyer, E.J., Wallace, E.K, Strawbridge, M.L., Libes, D.E., Young, C.V., "AMRF Network Communications," NBSIR 88-3816, June 1988 .

[SCHE89] Scheer, August-Wilhelm, 1989, Enterprise-wide data modelling, (Springer-Verlag, Berlin, Germany).

[SENE91-1] Senehi, M.K., Wallace, S., Wallace, E., Ray, S., and Barkmeyer, E., "Manufacturing Systems Integration Control Entity Interface Document," NISTIR 4626, June 1991.

[SENE91-2] Senehi, M.K., Barkmeyer, E., Ray, S., and Wallace, E., "Manufacturing Systems Integration Initial Architecture Document," NISTIR 4682, September 1991.

[SMIT88] Smith, Brad, and Rinaudot, Gaylen, 1988, Product data exchange specification, NISTIR 88-4004, (National Institute of Standards and Technology, Gaithersburg, Maryland).

[STIC92] Stickman, John F. and Rosenthal, Howard G., "CITIS: Gateway to Defense Industrial Base Productivity, Published in CALS Journal, Volume 1, Number 3, Page 83, Fall 1992 .

[THOM89] Thompson, Vince, and Graefe, Udo, 1989, CIM -- a manufacturing paradigm, International Journal of Computer Integrated Manufacturing, 2, 290-297.

[USA89] U.S. Tag to ISO TC 184, "U.S. Tag to ISO TC 184 Program of Work Working Draft 1.0 - N 244," available from NEMA Tag Administrator, August, 1989.

[WEST88] Weston, R., Gascoine, J., Rui, A., Hodgson, A., Sumpter, C., and Coutts, I., 1988, steps towards information integration in manufacturing, International Journal of Computer Integrated Manufacturing, 1, 140-153.

[WINN88] Winner, Robert I., Pennell, James P., Bertrand, Harold E., and Slusarczuk, Marko M. G., 1988, The role of concurrent engineering in weapons system acquisition, IDA Report R-338, (Institute of Defense Analysis, Alexandria, Virginia). 

